\title{
Conditional Upregulation of KCC2 selectively enhances neuronal inhibition during seizures
}

Goulton, $\mathrm{CS}^{1 *}$, Watanabe, $\mathrm{M}^{2 *}$, Cheung, $\mathrm{DL}^{1}$; Wang, $\mathrm{KW}^{1}$, Oba, $\mathrm{T}^{2}$, Khoshaba, $\mathrm{A}^{1}$, Lai, $\mathrm{D}^{1}$, Inada, $\mathrm{H}^{2}$, Eto, $\mathrm{K}^{2,3}$, Nakamura, $\mathrm{K}^{2,3}$, Power, $\mathrm{JM}^{1}$, Lewis, $\mathrm{TM}^{1}$, Housley, GD ${ }^{1}$, Wake, $\mathrm{H}^{2,4}$, Nabekura, $\mathrm{J}^{2,3+}$, Moorhouse, $\mathrm{AJ}^{1,2+}$

${ }^{1}$ Department of Physiology, School of Medical Sciences, UNSW Sydney, Australia;

${ }^{2}$ National Institutes for Physiological Sciences, Okazaki, Japan; ${ }^{3}$ The Graduate University for Advanced Studies (SOKENDAI), ${ }^{4}$ Division of System Neuroscience, Kobe University

Graduate School of Medicine

${ }^{*}$ equal contributions; ${ }^{+}$corresponding authors

Authors contributions: AJM and JN conceived the experiments, CG, DC, MH, AJM, AK, KW, DL, conducted experiments and/or analysis, TO, CG, DC managed animals, HI, KE, JP, HW, TL, GH, AJM, JN provided reagents, expertise and supervision, CG, DC, AJM, MW, HW, JN designed and co-ordinated the experiments, AJM drafted and wrote the manuscript, all authors contributed to manuscript revision.

Authors for correspondence:

Andrew J Moorhouse, School of Medical Sciences, UNSW Australia.

Junichi Nabekura, National Institutes for Physiological Sciences, Okazaki, Japan

Funded by UNSW Faculty Research Grant (AJM), National Health and Medical Research Council of Australia (AJM), \& Core Research of Evolutional Science \& Technology, Japan Science and Technology Agency (JN). DC is the recipient of an Australian Postgraduate Research Award. 


\section{Abstract / Summary.}

Efficacious neuronal inhibition is sustained by the neuronal $\mathrm{K}^{+} \mathrm{Cl}^{-}$co-transporter $\mathrm{KCC} 2$, and loss of KCC2 function through injury or mutation is associated with altered GABAergic signalling and neuronal seizures. Here we report a transgenic mouse with conditional KCC2 overexpression that results in increased membrane transport function. Increased $\mathrm{KCC} 2$ has little impact on behavioural and in vitro assays of neuronal excitability and GABAA receptor responses under resting conditions. In contrast, increased KCC2 imparts resistance to seizurelike neuronal activity in hippocampal slices and prevents the progression of mice into behavioural status epilepticus following multiple kainic acid doses. Our results demonstrate a transgenic mouse to facilitate investigations into the role of $\mathrm{KCC} 2$ in brain function, and provide a proof of principle that targeting $\mathrm{KCC} 2$ may be an effective way to selectively enhance neuronal inhibition to mitigate against diseases that involve an imbalance between excitation and inhibition.

\section{Introduction}

Brain function depends on the appropriate balance of neuronal excitation and neuronal inhibition across neural networks. Efficacious hyperpolarizing neuronal inhibition at $\gamma$-amino -butyric acid (GABAA) receptors relies on $\mathrm{Cl}^{-}$influx secondary to the capacity of the $\mathrm{K}-\mathrm{Cl}$ cotransporter $(\mathrm{KCC} 2)$ to maintain a low resting intracellular $\mathrm{Cl}^{-}$concentration $\left(\left[\mathrm{Cl}^{-}\right]_{\mathrm{i}}\right)$ (Payne et al., 1996; Kaila et al., 2014). KCC2 is, however, dynamic in its expression levels and function, and therefore in its contribution to $\left[\mathrm{Cl}^{-}\right]_{\mathrm{i}}$ homeostasis and neuronal inhibition. In developing neurons functional $\mathrm{KCC} 2$ is minimal and activation of GABA receptors can elicit $\mathrm{Cl}^{-}$efflux and a resultant depolarisation (Rivera et al., 1999; Ben-Ari et al., 2007; Inada et al., 2011). A conversion towards this immature, excitatory GABA signalling phenotype is seen in 
adult neurons when KCC2 function decreases following brain injuries or traumas (Kahle et al., 2008; Kaila et al., 2014). A particularly strong association is evident in both rodent models and in humans, between reduced KCC2 function and impaired inhibitory control in the pathophysiology of epilepsy and seizures. The excessive neuronal activity associated with seizures causes a loss of KCC2 transport function in rodent models (Rivera et al., 2004; Fiumelli et al., 2005; Pathak et al., 2007; Wake et al., 2007; Silayeva et al., 2015) and consistently, some neurons within the epileptic foci of excised temporal lobe tissues from drug refractory epilepsy patients show reduced $\mathrm{KCC} 2$ function and less efficacious $\mathrm{GABA}_{\mathrm{A}}$ receptor-mediated inhibition (Cohen et al., 2002; Huberfeld et al., 2007). The possibility that this reduced KCC2 may actually be causative for seizures is suggested by the high seizure susceptibility seen in transgenic mice with reduced KCC2 expression (Woo et al., 2002; Tornberg et al., 2005), and furthermore by the recent discovery of loss of function mutations in KCC2 in families with different forms of hereditary epilepsies (Kahle et al., 2014; Puskarjov et al., 2014; Stodberg et al., 2015; Saitsu et al., 2016). KCC2 also has transportindependent actions to stabilize dendritic spines (Li et al., 2007) and these epilepsyassociated mutations may both reduce $\mathrm{Cl}^{-}$extrusion capacity and/or impair spine stability (Puskarjov et al., 2014; Saitsu et al., 2016). Hence, deficits in KCC2 may confer an increased susceptibility to seizure initiation, and seizure activity may be further sustained through activity induced KCC2 downregulation.

A simple conclusion from the inverse correlation between KCC2 function and seizures is that enhancing KCC2 function could potentially mitigate against seizure induction in susceptible individuals, and circumvent a vicious cycle of seizure induced loss of efficacious neuronal inhibition. Indeed, the signalling pathways which modulate KCC2 activity, and the protein itself, have been suggested as key targets for the treatment of drug refractory epilepsy (Silayeva et al., 2015; Kahle et al., 2016). KCC2 enhancers may also find 
therapeutic value in various brain traumas associated with altered $\mathrm{Cl}^{-}$homeostasis, including axotomy, blunt trauma, ischemia and chronic pain (Wu et al., 2016). Such $\mathrm{Cl}^{-}$extrusion enhancing drugs have been shown to restore impaired neuronal inhibition in spinal cord circuits of peripheral nerve injured mice and relieve symptoms of chronic pain and spasticity (Gagnon et al., 2013; Liabeuf et al., 2017). However, the effects of specifically and directly enhancing KCC2 expression or function in the forebrain, and how this impacts on seizures in vivo, has yet to be evaluated. Given the myriad of changes in signalling pathways and ion concentrations that occur in hyperactive neural circuits in vivo, it may be over-simplistic to assume that agents that act to increase $\mathrm{KCC} 2$ in cellular models can similarly reduce $\left[\mathrm{Cl}^{-}\right]$and enhance inhibition in the epileptic brain. Activity-dependent post translational modifications of KCC2 activity may turn off KCC2 transport (Rivera et al., 2004; Fiumelli et al., 2005; Kahle et al., 2013), and negate efforts to increase KCC2 expression and function. In addition, extracellular $\mathrm{K}^{+}$increases during seizures and hyperexcitability may even reverse the direction of $\mathrm{KCC} 2$ mediated $\mathrm{Cl}^{-}$transport, facilitating depolarizing GABA responses via $\mathrm{HCO}_{3}{ }^{-}$and $\mathrm{Cl}^{-}$efflux (Kaila et al., 2014). In such a scenario, the loss of $\mathrm{KCC} 2$ during seizures may be an adaptive response to protect against the build-up of external $\mathrm{K}^{+}$and/or $\left[\mathrm{Cl}^{-}\right] \mathrm{i}$ (and water) loading. Although a detailed modelling study has suggested $\mathrm{KCC} 2$ downregulation contributes to exacerbating in vivo seizures (Buchin et al., 2015), in hippocampal slice models of seizures, blocking KCC2 can reduce extracellular $\mathrm{K}^{+}$ accumulation and seizure-like after-discharges (Viitanen et al., 2010; Hamidi \& Avoli, 2015).

In short, it is very unclear as to the in vivo functional consequences on neuronal inhibition and seizure phenotypes in response to increased KCC2. To directly address how KCC2 modulation impacts on adult brain function and excitability, we generated a transgenic mouse where KCC2 could be overexpressed. Given that precocious overexpression of KCC2 can alter the typical patterns of neural circuit development, it was important to utilize a 
conditional transgenic mouse strategy in which we had temporal control of KCC2 overexpression in adult brain. Our simple hypothesis was that overexpression of KCC2 would increase neuronal $\mathrm{Cl}^{-}$transport function and enhance neuronal inhibition, and we evaluated this using both in vitro and in vivo assays of neuronal excitability. Our results characterise this important mouse model, and demonstrate that enhanced KCC2 can selectively enhance GABAergic neuronal inhibition in hyperactive circuits, and can thereby mitigate against the severity of seizures in some in vivo models.

\section{Results.}

Conditional overexpression of KCC2 in the transgenic mice.

To investigate the impact of $\mathrm{KCC} 2$ overexpression on neural circuit function in the adult brain we utilized a conditional transgenic mouse strategy to allow temporal control of KCC2 expression. We employed the tetracycline inducible gene expression system (Gossen \& Bujard, 1992) and generated a Tet-Off KCC2 mouse, in which KCC2 overexpression was driven by withdrawing doxycycline (Dox) from the diet (Figure 1A). The tetracycline operator construct (tetO) was inserted immediately upstream of the KCC2 translation initiation site (KCC2-tetO mice), and these $\mathrm{KCC} 2$-teto mice were crossed with the CAMKII $\alpha$-tTA mice (Mayford et al., 1996), where the tetracycline trans activator sequence (tTA) was expressed under control of the Ca-Calmodulin kinase $2 \alpha$ promotor. The transgenic mice could express either or both of the tTA-CaMKII $\alpha$ (tTA) and KCC2-tetO (KCC2) alleles, but only in mice expressing both alleles (tTA-KCC2) was KCC2 overexpression inducible by the absence of Dox. Mice were raised on Dox-laced chow, and within days after withdrawing Dox from the diet, marked overexpression of KCCC2 mRNA was observed in the forebrain in tTA-KCC2 mice (Figure 1B). At the protein level, withdrawal of Dox for 7 days resulted in a two to three-fold increase in KCC2 in cortex, 
amygdala and hippocampus as compared to wild type C57B16 mice, or tTA-KCC2 mice maintained on Dox (Figure 1C). Increases in KCC2 protein were apparent after 2 days off Dox and appeared to continue to increase with prolonged Dox withdrawal (Supplemental Figure 1). The increase in KCC2 protein expression levels in tTA-KCC2 mice after Dox withdrawal was gradually reversed once the mice were returned to a diet containing Dox (Figure 1C).

Overexpression of KCC2 confers increased membrane KCC2 transport function.

A significant proportion of KCC2 can exist in cellular localisations distinct from the membrane pools of functional oligomeric KCC2 (Watanabe et al., 2009). Furthermore, KCC2 function is regulated by phosphorylation (Kahle et al., 2013), and hence an increase in protein expression levels does not necessarily imply an increase in membrane transport capacity. To quantify $\mathrm{KCC} 2$ transport, we used $\mathrm{NH}_{4} \mathrm{Cl}$ application coupled with a fluorescence assay using the $\mathrm{pH}$-sensitive membrane permeant fluorophore, BCECF-AM. Bath application of $\mathrm{NH}_{4} \mathrm{Cl}$ (10 mM, 3-5 minutes) to hippocampal slices from tTA-KCC2 mice that had been pre-loaded with BCECF, caused an initial alkalinisation due to passive influx of $\mathrm{NH}_{3}$ and a corresponding increase in BCECF fluorescence (Boron and De Weer, 1976). $\mathrm{KCC} 2$ can also transport $\mathrm{NH}_{4}^{+}$as a surrogate for $\mathrm{K}^{+}$, and active influx of $\mathrm{NH}_{4}^{+}$ acidifies the internal $\mathrm{pH}$ resulting in decreased BCECF fluorescence (Boron \& De Weer, 1976; Titz et al., 2006). Importantly, this assay challenges KCC2 with an imposed ionic load, rather than simply measuring resting $\mathrm{Cl}^{-}$or EGABA, which may be a less sensitive measure of $\mathrm{KCC} 2$ function. All bath solutions in these experiments contained bumetanide $(10 \mu \mathrm{M})$ to reduce any $\mathrm{NKCC} 1$ contribution to the fluorescent response. Examples of single neuron responses to $\mathrm{NH}_{4} \mathrm{Cl}$ are shown in Figure 2B. Repeated application of $\mathrm{NH}_{4} \mathrm{Cl}$ in the presence of furosemide $(0.5 \mathrm{mM})$ reduced the acidification component of the fluorescent 
response, consistent with a KCC2-mediated transport (Fig. 2B). A significantly greater acidification following $\mathrm{NH}_{4} \mathrm{Cl}$ perfusion was seen in Dox off tTA-KCC2 mice as compared to Dox on tTA-KCC2 mice (Figure 2C), indicating that overexpression of KCC2 in Dox off mice is associated with an increase in $\mathrm{KCC} 2$ mediated membrane transport function.

Increased KCC2 does not impact on locomotion and exploratory behaviours.

The open field and elevated plus maze assays are frequently used to evaluate agents which enhance neuronal inhibition, and should specifically detect sedative and/or anxiolytic effects (Kralic et al., 2002). As shown in Figure 3A, there was no significant difference in the total distance moved in either assay for the tTA-KCC2 Dox on vs Dox off cohorts, nor amongst any of the control or test groups. Similarly, there was no significant differences between the different mouse groups in the amount of time spent in the centre of the open field, nor the proportion of entries into the open arms of the elevated plus maze, two behaviours characteristic of anxiolytic drugs. Although withdrawal of Dox in tTA-KCC2 mice induces increased KCC2 expression and membrane transport, it doesn't induce obvious impairments in activity levels, nor does it induce any anxiolytic effects in these assays.

\section{Basic properties of synaptic transmission and muscimol responses in hippocampal slices}

To examine if upregulation of $\mathrm{KCC} 2$ alters neuronal excitability under basal or resting conditions we utilized field potential recordings in hippocampal slices, enabling the evaluation of population responses in neurons with undisturbed ionic milieu. The synaptically-evoked population response in mice with upregulated KCC2 (tTA-KCC2 mice, Dox Off) appeared the same as in three different control mice cohorts (tTA-KCC2 mice, Dox on, and KCC2 mice with or without Dox), and there was no differences amongst the groups in regards to the stimulus-response relationship, either at room temperature $\left(22-24^{\circ} \mathrm{C}\right)$, or at an elevated bath temperature $\left(30-32^{\circ} \mathrm{C}\right.$; Fig $\left.4 \mathrm{~A}\right)$. This suggests that neurons with increased 
KCC2 did not require stronger synaptic inputs to depolarize them to their action potential threshold, as may be predicted if, for example, they were more hyperpolarized at rest. Application of the GABAA receptor agonist muscimol led to a concentration-dependent and reversible decrease in the amplitude of the population spike (Figure 4B). The muscimol concentration-response curves for all four experimental groups were averaged and then fit with the Hill equation to derive IC50s of $1.5 \pm 1.2(\mu \mathrm{M}$, mean \pm SEM) for the KCC2 Dox On mice; $1.4 \pm 1.2$ for the KCC2 Dox Off mice; $1.4 \pm 1.2$ for the tTA-KCC2 Dox On mice; and $0.9 \pm 1.2$ for the tTA-KCC2 Dox Off, this latter group representing increased KCC2 expression. A post-hoc comparison between tTA-KCC2 Dox Off and tTA-KCC2 Dox On revealed no significant difference in IC50s (ANOVA, $p=0.04$; Bonferroni's test: $p=0.16$ ). Hence upregulation of KCC2 did not cause a significant increase in the muscimol potency.

\section{Increased KCC2 reduces seizure susceptibility in vitro}

The above results suggest no differences in neuronal excitability or GABA receptor responses in the resting hippocampal slice. We next examined if upregulation of KCC2 impacted on neuronal excitability when neural circuit activity was increased by simulated seizure activity. Two different protocols were used, the first involved repeatedly applying a tetanus $(100 \mathrm{~Hz}$, 1s) to the afferent pathways which could induce a spontaneous afterdischarge (AD) recorded in the CA1 pyramidal layer (Higashima et al., 2000). Tetani were applied every 10 minutes, and after the $3^{\text {rd }}$ or $4^{\text {th }}$ tetanus the $\mathrm{AD}$ pattern stabilized to a brief 5-20sec period of ADs consisting of typically 5-10 small $(\approx 1 \mathrm{mV})$ voltage deflections (Fig. 5A). Such ADs were generally absent in slices from mice overexpressing KCC2 (Fig. 5A). The incidence of ADs was similar in the slices from the three control groups (KCC2 mice dox on 6/7 slices, KCC2 mice Dox off 6/7 slices, tTA-KCC2 mice Dox on 7/7 slices, 5 mice per group) and were of a similar number when present (Fig 5B). In contrast, ADs were significantly less common, only 
seen in one from 7 slices from five tTA-KCC2 Dox Off mice, giving rise to a significantly reduced mean $\mathrm{AD}$ frequency (Fig 5B). We also examined altered neuronal excitability in hippocampal slices perfused with Mg-free aCSF with elevated $\mathrm{K}^{+}$(Mody et al., 1987). Perfusion of this Mg-free aCSF induced spontaneous spike discharges recorded at the extracellular electrode placed in the CA1 pyramidal cell layer (Fig 5C). In the three control mice cohorts, these spontaneous spikes were observed within about 5-10 mins after switching to the zero- $\mathrm{Mg}^{2+}$ solution, and stabilized at an approximate frequency of 0.2 to $0.5 \mathrm{~Hz}$ (Fig. 5D). The latency to the appearance of spontaneous spikes was significantly longer in slices from KCC2 upregulated tTA-KCC2 Dox off mice, and the frequency of spontaneous spikes was significantly decreased in these slices (Figure 5D). In all slices, the spontaneous spikes rapidly disappeared once the perfusate returned to the standard, $\mathrm{Mg}^{2+}$-containing aCSF. Together these results clearly show that the development of hyperexcitability in hippocampal slices is significantly reduced by KCC2 upregulation.

\section{Increased KCC2 prevents progression into Kainic Acid-induced Status Epilepticus}

Kainic acid activates glutamate AMPA/kainate receptors and induces convulsions in rodents that can progress into a full status epilepticus (SE) (Ben-Ari \& Cossart, 2000). To induce a more robust progression into SE without excessive mortality, and to also examine the threshold for SE more closely, we utilized a ramp-up dosing protocol and scored behavioural seizures using a modified Racine scale (McKhann et al., 2003; Tse et al., 2014). Mice were injected with a low dose of kainic acid $(5 \mathrm{mg} / \mathrm{kg})$ every 30 mins until SE was observed, defined as a stage 4 seizure followed by continuous seizure behaviour or death. Figures 6A, $6 \mathrm{~B}$ shows the patterns of seizure phenotypes in response to repetitive kainic acid doses for the tTA-KCC2 mice with Dox on and Dox off. At $\approx 15 \mathrm{mg} / \mathrm{kg}$, the control mice cohorts (tTAKCC2, Dox on; KCC2 Dox on and Dox off) typically experienced convulsive seizures with loss of posture, and progressed into SE (Figure 6A, 6C) whereas mice with upregulated 
KCC2 (tTA-KCC2) were relatively resistant to progression into SE, even when the dose was escalated to $50 \mathrm{mg} / \mathrm{kg}$ in total (Figure $6 \mathrm{~B}, 6 \mathrm{C}$ ). Indeed only 1 of five tTA-KCC2 Dox off mice experienced SE (at $50 \mathrm{mg} / \mathrm{kg}$ ) whereas all 15 mice from the control cohorts experienced $\mathrm{SE}$ at total doses of $25 \mathrm{mg} / \mathrm{kg}$ or lower. This important result was replicated using the transgenic mice in Japan, prior to importation to Australia. In these experiments, 9 out of 10 control mice (either tTA-KCC2 Dox on or WT siblings) progressed into SE (at total doses up to $20-40 \mathrm{mg} / \mathrm{kg}$ ) while none out of five tTA-KCC2 Dox off mice experienced SE at total maximal doses up to $30-50 \mathrm{mg} / \mathrm{kg}$. In conclusion, the results clearly indicate that upregulation of $\mathrm{KCC} 2$ imparts a marked resistance to the progression into kainic acid induced status epilepticus.

\section{No effect of increased KCC2 on PTZ induced seizure responses}

Finally, we investigated whether the seizure-resistance conferred by KCC2 upregulation in the escalating kainic acid challenge generalised across to other in vivo seizure models. The pentyltetrazole (PTZ) model is widely used to evaluate anticonvulsant drugs, with subcutaneous injections of this $\mathrm{GABA}_{\mathrm{A}}$ receptor antagonist inducing a rapid progression through a well characterised series of behavioural seizure states. Mice from control (KCC2) and test (tTA-KCC2) genotypes, with and without Dox, were pre-administered either vehicle (30\% ethanol in $0.9 \%$ saline, $0.1 \mathrm{ml}$, ip) or diazepam $(3 \mathrm{mg} / \mathrm{kg}$ in vehicle, ip) followed by a single dose of PTZ ( $85 \mathrm{mg} / \mathrm{kg}, s c$ ). Seizures were scored blindly from video recordings based on a modified Racine scale of 6 stages (Luttjohann et al., 2009). In the vehicle cohort, all mice groups rapidly progressed through to higher grade convulsive and tonic seizures within 10-20 mins after injection. There was no significant effect of KCC2 upregulation on the response to PTZ. The latency to the first twitch seizure, and the total cumulative seizure score over the 30 mins post-PTZ is shown in Supplemental Figure 2A. Pretreatment with diazepam reduced the severity of the subsequent response to PTZ, as expected, but again 
there was no significant differences amongst the mice cohorts in the extent to which diazepam prolonged the seizure latency or reduced the total seizure score. In short, we could not detect any effect of KCC2 overexpression on the response to PTZ, nor on the effect of diazepam pre-treatment on the PTZ induced seizure response.

\section{Discussion}

$\mathrm{KCC} 2$ plays a key role in neuronal $\mathrm{Cl}^{-}$homeostasis and the efficacy of neuronal inhibition mediated by activation of GABAA and glycine receptors in brain and spinal cord (Doyon et al., 2016). A downregulation of KCC2 function and expression occurs in a range of brain traumas and disease (Kahle et al., 2008; Kaila et al., 2014; Wu et al., 2016), including epilepsy (Cohen et al., 2002), chronic allodynia and spasticity from peripheral nerve injury (Coull et al., 2003; Boulenguez et al., 2010; Eto et al., 2012; Liabeuf et al., 2017), axotomy (Nabekura et al., 2002) and ischemia (Papp et al., 2008). Furthermore, alterations in $\mathrm{Cl}^{-}$ homeostasis have been associated with cognitive deficits in autism spectrum disorders, Downs Syndrome, schizophrenia and age-related dementia (Deidda et al., 2015; Merner et al., 2015; Ferando et al., 2016; Tang et al., 2016; Ben-Ari, 2017). Consequently, intense interest has developed in manipulating $\mathrm{KCC} 2$ activity to potentially treat a range of different brain disorders. We have therefore established a conditional transgenic mouse to allow the selective overexpression of KCC2, and to facilitate the study of how increased KCC2 effects neuronal excitability and brain function in vivo.

Withdrawal of doxycycline from the diet lead to a rapid and reversible increase in KCC2. Within two days of withdrawing doxycycline, KCC2 mRNA and protein levels were increased. Protein levels increased by 2-3-fold by $\approx 7$ days after Dox withdrawal. When neurons were challenged with an ionic load $\left(\mathrm{NH}_{4} \mathrm{Cl}\right)$, enhanced $\mathrm{NH}_{4}{ }^{+}$membrane transport 
was seen in slices from transgenic mice, so at least some of this overexpressed KCC2 is functional. The increase in functional transport in this fluorescent assay was modest, although these fluorescent responses were averaged across multiple CA1 neurons within a slice, and not every cell would be expected to over express $\mathrm{KCC} 2$. In a series of transgenic mice lines, in which the tTA-tetO system was coupled to drive GFP fluorescence, between $30-70 \%$ of CA1 neurons failed to express GFP (Wu et al., 2016). The cellular extent to which $\mathrm{KCC} 2$ is overexpressed in our current tTA-KCC2 mouse after Dox withdrawal remains to be quantified.

The increase in functional $\mathrm{KCC} 2$ was sufficient to reduce the progression into seizures, both in vitro and in vivo. A striking effect was seen in two in vitro models: tetanic-induced afterdischarges were virtually absent while spontaneous spikes following perfusion with 0 $\mathrm{Mg}^{2+}$ hyperexcitable solution took longer to be induced and were of reduced frequency. This altered seizure threshold was seen in the absence of any major effects on basal population spikes or on $\mathrm{GABA}_{\mathrm{A}}$ receptor responses in non-seizure or "basal" conditions. We propose that under such basal or resting conditions, neurons have sufficient functional KCC2 (and other transporters) to regulate intracellular $\mathrm{Cl}^{-}$effectively, and additional $\mathrm{KCC} 2$ transporters have minimal impact on resting membrane potentials or excitability. Under resting or approximate equilibrium conditions, then the $\left[\mathrm{Cl}^{-}\right]$i set point should be established by the relative permeability for $\mathrm{Cl}^{-}$and the driving forces for the ions that are actively transported across the membrane (e.g., $\mathrm{EK}^{+}, \mathrm{ECl}^{-}$and $\mathrm{ENa}^{+}$for $\mathrm{KCC} 2$ and $\mathrm{NKCC} 1$ ), with possible contributions from impermeant anions (Glykys et al., 2017). Increasing the relative number of KCC2 transporters present doesn't appear to alter this set point. However, when the neural circuits become more active, such as following tetanic stimulation or when made hyperexcitable by $0 \mathrm{Mg}^{2+}$, then we propose that endogenous $\mathrm{KCC} 2$ cannot maintain $\left[\mathrm{Cl}^{-}\right]$ homeostasis, $\left[\mathrm{Cl}^{-}\right]_{\mathrm{i}}$ becomes elevated, GABA inhibition is consequently weakened, and this 
contributes to spontaneous hippocampal discharges. When $\mathrm{KCC} 2$ is overexpressed, $\left[\mathrm{Cl}^{-}\right]$i and hence GABA inhibition is maintained during circuit hyperactivity, and seizures are reduced. A similar mechanism is proposed to account for the in vivo results. Under basal or nonseizure conditions, there is little effect of further increasing KCC2 transport on neuronal inhibition, and no sedation nor clear effects on locomotion or exploratory behaviour were seen in mice overexpressing $\mathrm{KCC} 2$. However, once the mice are challenged with by escalating kainic acid doses - then neural circuits become hyperactivated, $\left[\mathrm{Cl}^{-}\right]_{\mathrm{i}}$ builds up, and inhibition becomes less efficacious. A build-up of $\left[\mathrm{Cl}^{-}\right]$in pyramidal neurons occurs during seizures and may trigger loss of functional inhibition and ictal events (Lillis et al., 2012; Glykys et al., 2017; Sulis Sato et al., 2017), as our data also supports. We propose that enhancing $\mathrm{KCC} 2$ enables better control of $\left[\mathrm{Cl}^{-}\right]$i and maintenance of neuronal inhibition. The initial and more modest seizures don't seem to be prevented by KCC2 upregulation, but the progression of seizures into a sustained, self-propagating status epilepticus was prevented by increasing $\mathrm{KCC} 2$. Consistently, optogenetic in vivo activation of interneurons in the subiculum during the early stages of epileptogenesis can inhibit seizures, but their activation after GABA transmission has shifted to a depolarizing phenotype becomes less effective and can even exacerbate seizures (Wang et al., 2017). Hence enhancing $\mathrm{Cl}^{-}$extrusion capacity may not prevent seizures, but may reduce the progression to a self-sustaining state associated with depolarizing GABA and loss of inhibition. This supports previous conclusions derived from the characterisation of the KCC2 S940A transgenic mouse, which mimics the specific downregulation of KCC2 during hyperactivity (Silayeva et al., 2015). Both in vitro and in vivo, seizure latency was unaffected, but the seizure severity was exacerbated with the greater loss of KCC2 membrane function. Similarly, blocking NKCC1 mediated $\mathrm{Cl}^{-}$influx with bumetanide doesn't prevent seizures, but can reduce their duration and severity (Sivakumaran \& Maguire, 2016). Our data support the idea that enhancing KCC2 expression and function 
can be protective against seizures, and particularly in curbing their progression and severity. However, the generalisation of this neuroprotective strategy may be questioned by the complete lack of any protection seen in the PTZ models. Although PTZ and kainic acid induce seizures via different cellular targets, agents potentiating $\mathrm{GABA}_{\mathrm{A}}$ receptors are effective in reducing PTZ seizure severity (as we also reported for diazepam). It may be that the rapid escalation of seizures in response to PTZ overwhelmed the capacity of the overexpressed $\mathrm{KCC} 2$ to maintain $\mathrm{Cl}^{-}$homeostasis and robust inhibition. Regardless, the result highlights that enhancing $\mathrm{KCC} 2$ may not be a panacea to reduce all forms of seizures or epilepsy.

In conclusion, we present a conditional transgenic mouse in which functional KCC2 overexpression can be rapidly induced by dietary manipulation. Increasing KCC2 had little detectable effects on excitability or behaviour under non-pathological, resting conditions, strengthening its appeal as a potential therapeutic target and consistent with studies using pharmacological enhancement of KCC2 (Gagnon et al., 2013; Liabeuf et al., 2017).

Overexpressing $\mathrm{KCC} 2$ was able to reduce the severity of seizures, indicating that neuronal inhibition may be selectively enhanced during hyperactive states by KCC2 upregulation. Our results suggest that the loss of KCC2 that can accompany seizures and epilepsy may be detrimental to restoring neural circuit homeostasis. Our mouse should facilitate investigations into the consequences of modulating $\mathrm{KCC} 2$ in a broad range of pathophysiological situations, helping guide potential therapeutic applications of targeting $\mathrm{Cl}^{-}$ homeostasis to treat brain disorders.

\section{Methods.}


Experiments were approved by the UNSW Australia Animal Care and Ethics Committee and by the National Institutes of Natural Sciences of Japan, and adhered to the Guidelines for Animal Care and Welfare of the National Health and Medical Research Council of Australia.

\section{Generation and Maintenance of the Transgenic mouse colony}

We first generated a KCC2 STOP-tetracycline operator (tetO) knock-in mouse (Tanaka et al., 2010). Homologous recombination was used to insert the KCC2 gene (from mouse BAC RP23-6103, Invitrogen) into a loxP-Neo-STOP-tetO plasmid (a kind gift from Dr kenji Tanaka, (Tanaka et al., 2010) which was electroporated into 129Sv/EvTac ES cells. Targeted ES cells were injected into C57B16J mice to generate a KCC2 STOP-tetO knock-in mouse. These mice were then crossed with ROSA-FLiP mice to excise the neoSTOP plasmid cassette to generate a KCC2-tetO mouse, with tetO inserted upstream of the $\mathrm{KCC} 2$ translation initiation site. KCC2-tetO mice were crossed with a calcium calmodulin-dependent kinase II $\alpha(\mathrm{CAMKII} \alpha)$-tetracycline transactivator (tTA) mouse, which expresses tTA in forebrain neurons ((Mayford et al., 1996); a kind gift from Dr Kenji Tanaka). Mouse were genotyped from tail tips using separate PCR primers against the CAMKII $\alpha$-tTA and KCC2-tetO inserts. The forward and reverse primers for tTA were 5'-AGGCTTGAGATCTGGCCATAC-3' and 5'-AAGGGCAAAAGTGAGTATGGTG-3', respectively, and the KCC2-tetO forward and reverse primers used were: 5'-AGCAGAGCTCGTTTAGTGAACCGT-3' and 5'TGGAAACTCAAAGCGAGGAACTGC-3' respectively.

Transgenic mice were maintained in both Japan and Australia, housed in a 12-12 light cycle with food and water ad libitum. Experiments were undertaken in Australia and/or Japan as indicated. Mice were raised and fed on doxycycline-laced chow (Australia: $600 \mathrm{mg} / \mathrm{kg}$; Gordons stock suppliers, Narrabri NSW; Japan: 100mg/kg; Oriental Yeast Co., Ltd, Tokyo) and 
Dox off mice were separated and fed with the same Dox-free chow for 6-10 days prior to experiments, or as indicated.

\section{Molecular and biochemical validation}

In situ hybridization (Japan; Fig. 1) was used to confirm overexpression of the KCC2 transcript. Adult (2-3 month) CamKII $\alpha$-tTA or tTA-KCC2 mice, either Dox on or Dox off were cardiac perfused with PBS followed by 4\% PFA in PBS and brains excised and postfixed overnight, before cryoprotection in $20 \%$ sucrose and embedding in OCT compound. The methods are described in detail in Ma et al., (2006). Sagittal cryosections $(30 \mathrm{uM})$ were washed and prepared as described (Ma et al., 2006) and hybridized with digoxigenin-labelled KCC2 cRNA probes (NCBI accession number NM_020333.2; corresponding to 3'-untranslated region 3981-5993 bp; coding region is 416-3763 bp). Colour substrates (NBT/BCIP; Roche) were used for colour development, and nuclear fast red (Vector lab, Burlingame, CA) was used for counter-staining.

To quantify KCC2 protein expression using Western blots, two approaches were used. In the first (Japan; Fig. 1; (Watanabe et al., 2009)), brains were excised from adult male and female mice (2-3 months) and sliced at $300 \mu \mathrm{M}$ using a Vibratome (Leica) in cold-aCSF. Regions of interest ( $1 \mathrm{~mm}$ diameter) were micropunched from each hemisphere, grouped and homogenized in lysis buffer (pH 7.4) on ice, containing Tris $\mathrm{HCl}(50 \mathrm{mM}), \mathrm{NaCl}(150 \mathrm{mM})$, EDTA (5 mM), complete protease inhibitor (Roche, Indiannapolis), 1\% (w/v) Triton X-100. Homogenate was centrifuged at $12,000 \mathrm{G}$ for $10 \mathrm{mins}$ at $4^{\circ} \mathrm{C}$ and supernatant was collected. Proteins were separated in $7.5 \%$ acrylamide gels transferred to Immobilon-P membranes (Millipore, Bedford, MA). Reactions were blocked in 1\% bovine serum albumin and membranes incubated overnight with the KCC2 (1:1000, Upstate Biotechnology, New York, now Millipore; Merck) or $\beta$ actin (1:10000, Sigma-Aldrich) primary antibodies at $4^{\circ} \mathrm{C}$. Blots 
were then incubated with HRP-conjugated secondary antibody (GE Healthcare UK Ltd., Buckinghamshire, England) for $1 \mathrm{~h}$ at room temperature and labelled protein visualized using enhanced chemiluminescence (ECL, GE Healthcare). Optical densities were quantified using Image J (NIH, Bethseda).

In the second method (Australia; Supp Figure 1), brains from adult KCC2 (control samples) and tTA-KCC2 mice, at different times after Dox withdrawal as indicated, were rapidly excised on to ice, and the hippocampi, cortices and cerebellum were dissected out and frozen for later homogenisation in 400ul RIPA lysis buffer (Cell Signaling) in the presence of protease (Sigma-Aldrich) and phosphatase (Roche) inhibitors. The supernatant was collected after centrifugation at $13000 \mathrm{rpm}$ for $20 \mathrm{mins}, 4^{\circ} \mathrm{C}$. Protein concentrations were determined with Biorad BCA assay and samples were denatured at $70^{\circ} \mathrm{C}$ for 10 minutes. $10 \mathrm{ug}$ RIPA extracted protein was separated using $4-12 \%$ Bis-Tris acrylamide gel, and transferred to PVDF using the iBlot dry transfer system for 9mins, blocked in 5\% skim milk and probed with polyclonal rabbit anti-KCC2 antibody (1:1000; cat\# 07-432; Upstate Biotechnology; Millipore), mouse anti-human transferrin receptor (1:1000; 13-6800; Invitrogen) or a monoclonal specific $\beta$ actin (1:35 000; A3854; Sigma Aldrich) primary antibody overnight at $4^{\circ} \mathrm{C}$. Blots were incubated with either peroxidase labelled anti-rabbit igG $(1: 10000$, Cell Signaling) or peroxidase labelled anti-mouse $\operatorname{IgG}(1: 10000$, Cell Signaling). Immunoreactive proteins were visualised using enhanced chemiluminescence (Thermo Scientific). Optical density measurements were performed using NIH Image J software.

\section{Imaging KCC2 transport in vitro using BCECF-AM}

Mice (6-18 weeks; Japan) were anaesthetized with isoflurane and subsequently pentobarbitone $(\approx 100 \mathrm{mg} / \mathrm{kg})$ and cardiac perfused with a cold, low $\mathrm{Na}^{+}$cutting solution containing (in mM: Sucrose 248; $\mathrm{MgCl}_{2} 1 ; \mathrm{CaCl}_{2} 1 ; \mathrm{MgSO}_{4} 1.25 ; \mathrm{NaH}_{2} \mathrm{PO}_{4} 2 ; \mathrm{KCl} 2$; 
$\mathrm{NaHCO}_{3} 26$; D-Glucose 10; 95\% O2 and 5\% CO2. Brains were rapidly excised and sliced at 300-350 uM in the coronal plane (Leica VT100S), and then incubated in the standard, recording aCSF containing (in $\mathrm{mM} ; \mathrm{NaCl} 150, \mathrm{KCl} 5, \mathrm{CaCl}_{2} 2, \mathrm{MgCl}_{2} 2, \mathrm{NaHCO}_{3} 25$, bubbled with $\left.95 \% \mathrm{O}_{2} / 5 \% \mathrm{CO}_{2}, \mathrm{pH} 7.4\right)$. After at least 1 hour, a single slice was transferred to a small loading chamber filled with aCSF and 50-100 $\mu \mathrm{M}$ of BCECF-AM (2', $7^{\prime}-$ bis $^{-}\left(2^{-}\right.$ carboxyethyl)-5-(and-6)-carboxyfluorescein) - acetoxymethyl ester; Invitrogen) along with some of the DMSO solvent (final volume $0.2-0.5 \%$ DMSO vol/vol) and supplemented with $0.1 \%(\mathrm{vol} / \mathrm{vol})$ pluronic acid. Slices were loaded for 30-40 mins and then transferred to the recording chamber mounted on the stage of an Olympus (BX61WI) multi-photon microscope (objective: 20X $0.95 \mathrm{NA}$ ) and continuously perfused with aCSF at room temperature.

BCECF fluorescence was excited using a Ti:Saphire mode-locked laser tuned to $790 \mathrm{~nm}$, with emissions collected above $535 \mathrm{~nm}$. A small region within the pyramidal cell layer, typically the CA1 subfield, with dye labelled neurons was identified and checked for fluorescent stability. Loading was variable and typically less than 10 fluorescent neurons were observed in a single field. $\mathrm{A} \mathrm{K}^{+}$-free, $\mathrm{NH}_{4} \mathrm{Cl}(10 \mathrm{mM})$ containing aCSF was bath applied for 3-5 minutes with images continuously acquired (Fluoview ver 4.1a) at a frame rate of 1.4 to $2.5 \mathrm{~Hz}$. Slices were then perfused with $0.5 \mathrm{mM}$ furosemide for at least 8 minutes and the application of the $\mathrm{NH}_{4} \mathrm{Cl}$ solution was repeated in the continued presence of furosemide. In some slices a further 10 minute period of washout of furosemide was followed by a $3^{\text {rd }}$ application of $\mathrm{NH}_{4} \mathrm{Cl}$. All solutions contained bumetanide $(10 \mu \mathrm{M})$ to negate any contribution of $\mathrm{NKCC} 1$ to the fluorescent signal. Image files were imported into Image $\mathbf{J}$ for analysis. Between 2-8 individual neurons were marked as regions of interest (ROIs) and their fluorescent signal intensity (FI) was quantified and normalised to that observed just prior to the start of $\mathrm{NH}_{4} \mathrm{Cl}$ application. The relative fluorescence in each ROI was averaged to give a single trace for each slice. The peak relative $\mathrm{FI}$ during $\mathrm{NH} 4 \mathrm{Cl}$, and 
the minimum relative FI which occurred 2 minutes following $\mathrm{NH}_{4} \mathrm{Cl}$ application, under control conditions and with furosemide, was quantified and compared across mice. For animals maintained on Dox diet, Dox was added to ACSF at $6 \mathrm{ng} / \mathrm{mL}$.

In vivo behaviour: Open field and Elevated Plus Maze

Male mice (11-18 weeks; Japan) were singly caged and transferred into the behavioural test room where they were acclimatized for 1-1.5 hours. Behavioural testing was performed between $3 \mathrm{pm}$ and $8 \mathrm{pm}$, with open field performed on day 1 and elevated plus maze performed on day 2. Both control (wild-type and tTA mice) and tTA-KCC2 mice were raised with Dox chow, which was withdrawn in the Dox off cohort 6-8 days prior to behavioural testing. The open field chamber consisted of an opaque Perspex square with equal sides of $40 \mathrm{~cm}$, with the centre area $(24 \times 24 \mathrm{~cm})$ comprising $36 \%$ of the field area. A single mouse was placed into the same corner and activity was recorded over 10 minutes. The elevated plus maze comprised of two raised and bisecting $130 \mathrm{~cm}$ long laneways of $10 \mathrm{~cm}$ width with walls of $10 \mathrm{~cm}$ height. One of the laneways had clear Perspex walls in each arm, defined as the open arm. An enclosed central area extended $5 \mathrm{~cm}$ into each are, resulting in closed and open arms of $60 \mathrm{~cm}$ each. A single mouse was placed into the central area facing towards the same closed arm, and its activity was monitored for the subsequent 10 minutes. One mouse jumped off the open arm during the trial and data for this mouse was excluded from further analysis. Ambient temperature and lighting was $25-30^{\circ} \mathrm{C}$ and typically $100-150$ lux, and apparatus was wiped clean with $70 \%$ ethanol or hyperchlorous solution between each trial. Movies were captured via a USB camera (Logicool HD720p, Logitech, Japan) mounted above the behavioural apparatus and analysed later by an observer blind to the genotype using Anymaze software (Woods Dale, Illinois). The centre of the mouse was used to determine the mouse's position, as this was identified in a subset of data as most consistently 
matching the manually scored data. Contrast was adjusted to minimize false detection events and all analysis was visually inspected to confirm valid scoring events.

\section{In vivo behaviour: Pentyltetrazole and Kainic Acid assays}

For the pentylenetetrazole (PTZ) induced seizure assay (Australia), mice of both sexes (8-14 weeks, gender balanced) were transferred to the recording room and acclimatized to the recording chamber for 30 minutes prior to starting experiments. The experimental chamber consisted of a clear Perspex box (15 cm width x $25 \mathrm{~cm}$ long x $15 \mathrm{~cm}$ high) into which were mounted a series of mirrors so that detailed observations of mouse facial features and behaviour could be recorded with an HD video camera mounted to the side of the chamber. 15 mins prior to PTZ injection mice were administered either vehicle (30\% ethanol in $0.9 \%$ saline, $0.1 \mathrm{ml}, s c$ ) or diazepam ( $3 \mathrm{mg} / \mathrm{kg}, 0.75 \mathrm{mg} / \mathrm{mL}$ of vehicle, $s c)$. PTZ ( $85 \mathrm{mg} / \mathrm{kg}$ in saline) was administered as a single $s c$ bolus, and behaviour was monitored for the appearance of a stage 5 seizure or for up to 60 mins, after which surviving mice were euthanized and tissues extracted. Video recordings were coded and scored later in a blind fashion according to a modified 6 stage Racine scale for PTZ (Luttjohann et al., 2009), where stage 3 and higher represented convulsive or tonic-clonic seizures. The latency to Stages 3 and 5 were quantified, and the dominant Stage each 5 minutes was tabulated to give a cumulative seizure score.

For the Kainic Acid (KA) induced seizure assay (Australia), male and female mice (8-14 weeks, gender balanced) were singly caged in the experimental room and left to acclimatize for 60 mins. Mouse behaviours were monitored by a camera mounted in front and above their cage and the experimenter was blinded to the genotype. Mice were injected with KA (Sigma, St Louis) using a dose escalation paradigm in which a modest does of $5 \mathrm{mg} / \mathrm{kg}$ was administered ip every 30-40 mins until a stage 4 or 5 seizure was observed. Seizure scoring 
used again a modified Racine scale characterised as follows: Stage 1, immobility; Stage 2 Straub tail, piloerection; Stage 3 brief convulsive seizure (twitch) and/or forelimb cycling; Stage 4 additional loss of posture, Stage 5 jumping, bouncing seizure. Stage 4-5 seizures were typically followed continued episodes of stage 3-5 seizures that could be interspersed with stage 1-2 seizures and that lasted at least $60 \mathrm{mins}$, although mice sometimes died during this SE and hence SE was defined here by the presence of at least two Stage 4 seizures. Dosing continued until SE was reached or until a total of $50 \mathrm{mg} / \mathrm{kg}$ had been administered. These experiments were also repeated with the Japanese colony, with a similar dosing escalation schedule and scoring system, except the experimenter was not blind to the genotype. Also, test and sibling controls were tested concurrently under the same conditions.

\section{Hippocampal slice electrophysiology}

Mice (Australia) of either sex (8-16 weeks) were anaesthetized with pentobarbitone (50 $\mathrm{mg} / \mathrm{kg}$, ip) and cardiac perfused with an ice cold, sucrose aCSF solution containing (in $\mathrm{mM}$ ): Sucrose, 230; $\mathrm{MgCl}_{2}, 1 ; \mathrm{CaCl}_{2}, 0.5 ; \mathrm{KH}_{2} \mathrm{PO} 4,1 ; \mathrm{KCl}, 2 ; \mathrm{NaHCO}_{3}, 26$; D-Glucose, 10; 95\% $\mathrm{O}_{2}$ and $5 \% \mathrm{CO}_{2}$. Brains were rapidly excised and sliced at $400 \mu \mathrm{M}$ in the sagittal plane (Leica VT1200) in the cold cutting solution before being transferred to a slice incubation solution filled with aCSF (in mM; $\mathrm{NaCl}, 125 ; \mathrm{KCl}, 2.5 ; \mathrm{NaH}_{2} \mathrm{PO}_{4}, 1.25 ; \mathrm{CaCl}_{2}, 2 ; \mathrm{MgSO}_{4}, 1$; $\mathrm{NaHCO}_{3}, 25$; bubbled with $95 \% \mathrm{O}_{2} / 5 \% \mathrm{CO}_{2}$, $\mathrm{pH}$ 7.4). In vitro seizure experiments were conducted at $32{ }^{\circ} \mathrm{C}$, while muscimol concentration responses were done at $24{ }^{\circ} \mathrm{C}$. The slice incubation chamber was set at the same temperature as the recording chamber. A single slice was transferred to the recording chamber and extracellular field potential responses were recorded from the CA1 region of the stratum pyramidale in response to stimulation of Schaeffer collateral afferent fibres. The recording electrode was a glass pipette filled with $\mathrm{aCSF}$ and the bipolar stimulating electrode was constructed of fine $(25 \mu \mathrm{m}) \mathrm{Ag}$ wires 
insulated up to the tip with Teflon connected to a constant current digital stimulus isolation unit (DS2A-Mkii, Digitimer). Acquisition was via an Axoclamp 900A (Molecular Devices), PowerLab (4/25T) and LabChart ${ }^{\mathrm{TM}}$ software (v7, ADInstruments), acquired at 5kHz following low-pass and high pass filtering at $0.1 \mathrm{~Hz}$ and $2 \mathrm{kHz}$, respectively (Powerlab, AD Instruments).

Once stable recordings were obtained from a slice, a series of single stimuli were applied to determine the stimulus intensity that produced a maximal and half maximal population spike (PS). Baseline responses were obtained at $0.1 \mathrm{~Hz}$ and only slices in which a clearly identified PS with a maximal amplitude of $>1 \mathrm{mV}$ were used for experiments. For concentration response experiments, stimuli at an intensity to produce an approximate $50 \%$ maximal response were applied continually at $0.1 \mathrm{~Hz}$ and different concentrations of muscimol were sequentially bath applied for at least 30 mins at each concentration. A set of control recordings were interspersed between every 2-3 muscimol concentrations, allowing at least 40 minutes for drug washout. Between 4-6 concentrations were obtained for each slice, and control responses flanking each concentration were averaged and used for normalisation of the data. PS amplitude was measured by interpolating the response amplitude between before and after the PS, and measuring from this extrapolated baseline to the response peak. Normalised data from each experiment was grouped and fit to the Hill equation using $\operatorname{Prism}^{\mathrm{TM}}$ (Graphpad, CA) to obtain the maximal inhibition, IC50 and Hill slope. Fits to the sets of data from different mice groups were done concurrently and constrained to have the same slopes. For the input-output curves, at least 3 evoked responses at each stimulus intensity were averaged to derive the PS amplitude value at that intensity. Responses were then normalised to the maximal PS amplitude for that slice, allowing for averaging of multiple slices within in each experimental group. 
To evaluate neuronal excitability in hippocampal slices, two seizure models were used. In the first (Higashima et al., 2000), control PS responses were initially evaluated to ensure stability and then a 10 second tetanic stimulus train at $100 \mathrm{~Hz}$ was applied to the Schaeffer Collaterals at a stimulus intensity that was just supramaximal. Stimulus trains were repeated every 10 minutes for 1 hour and the presence and number of afterdischarges were manually quantified. In the second protocol (Mody et al., 1987), control PS responses were again initially evaluated for amplitude and stability and then the bath was perfused with a zero $\mathrm{Mg}^{2+}$ solution consisting of (in $\mathrm{mM}$ ): $\mathrm{NaCl}, 125 ; \mathrm{KCl}, 5 ; \mathrm{NaH}_{2} \mathrm{PO}_{4}, 1.25 ; \mathrm{CaCl}_{2}, 2$; Glucose, 10; $\mathrm{NaHCO}_{3}, 26$, which produced spontaneous field potential transients (spikes) at the CA1 recording electrode. The latency to the appearance of these spontaneous spikes, and the frequency of these spikes was manually quantified. Spike frequency was determined from the time of 1 st spontaneous spike till the end of the perfusion period

For animals maintained on Dox diet, Dox was added to ACSF at $6 \mathrm{ng} / \mathrm{mL}$.

Data Analysis and Statistics.

All data are expressed as mean \pm SEM and were analysed using Prism ${ }^{\mathrm{TM}}$ (Graphpad, CA). Multiple genotypes and diet groups were compared using an ANOVA and with three post hoc comparisons preselected prior to analysis to maximize statistical power: i) Effect of Doxycycline Diet Alone: KCC2 Dox On vs. KCC2 Dox Off mice; ii) Effect of Genotype Alone: KCC2 Dox On vs. tTA-KCC2 Dox On mice; and iii) Effect of KCC2 Upregulation: tTA-KCC2 Dox On vs. tTA-KCC2 Dox Off mice.

\section{$\underline{\text { References }}$}

Ben-Ari Y (2017). NKCC1 Chloride Importer Antagonists Attenuate Many Neurological and Psychiatric Disorders. Trends Neurosci 40, 536-554. 
Ben-Ari Y \& Cossart R (2000). Kainate, a double agent that generates seizures: two decades of progress. Trends in Neurosciences 23, 580-587.

Ben-Ari Y, Gaiarsa JL, Tyzio R \& Khazipov R (2007). GABA: a pioneer transmitter that excites immature neurons and generates primitive oscillations. Physiological reviews 87, 1215-1284.

Boron WF \& De Weer P (1976). Intracellular pH transients in squid giant axons caused by CO2, NH3, and metabolic inhibitors. The Journal of general physiology 67, 91-112.

Boulenguez P, Liabeuf S, Bos R, Bras H, Jean-Xavier C, Brocard C, et al. (2010). Down-regulation of the potassium-chloride cotransporter $\mathrm{KCC} 2$ contributes to spasticity after spinal cord injury. Nature medicine 16, 302.

Buchin A, Huberfeld G, Miles R, Chizhov A \& Gutkin B (2015). Effects of a reduced efficacy of the KCC2 co-transporter in temporal lobe epilepsy: single neuron and network study. $B M C$ Neuroscience 16, P5.

Cohen I, Navarro V, Clemenceau S, Baulac M \& Miles R (2002). On the Origin of Interictal Activity in Human Temporal Lobe Epilepsy in Vitro. Science 298, 1418-1421.

Coull JA, Boudreau D, Bachand K, Prescott SA, Nault F, Sik A, et al. (2003). Trans-synaptic shift in anion gradient in spinal lamina I neurons as a mechanism of neuropathic pain. Nature 424, 938-942.

Deidda G, Parrini M, Naskar S, Bozarth IF, Contestabile A \& Cancedda L (2015). Reversing excitatory GABAAR signaling restores synaptic plasticity and memory in a mouse model of Down syndrome. Nature medicine 21, 318-326.

Doyon N, Vinay L, Prescott SA \& De Koninck Y (2016). Chloride Regulation: A Dynamic Equilibrium Crucial for Synaptic Inhibition. Neuron 89, 1157-1172.

Eto $\mathrm{K}$, Ishibashi $\mathrm{H}$, Yoshimura $\mathrm{T}$, Watanabe M, Miyamoto A, Ikenaka $\mathrm{K}$, et al. (2012). Enhanced GABAergic activity in the mouse primary somatosensory cortex is insufficient to alleviate chronic pain behavior with reduced expression of neuronal potassium-chloride cotransporter. The Journal of neuroscience : the official journal of the Society for Neuroscience 32, 16552-16559.

Ferando I, Faas GC \& Mody I (2016). Diminished KCC2 confounds synapse specificity of LTP during senescence. Nat Neurosci 19, 1197-1200.

Fiumelli H, Cancedda L \& Poo MM (2005). Modulation of GABAergic transmission by activity via postsynaptic Ca2+-dependent regulation of KCC2 function. Neuron 48, 773-786. 
Gagnon M, Bergeron MJ, Lavertu G, Castonguay A, Tripathy S, Bonin RP, et al. (2013). Chloride extrusion enhancers as novel therapeutics for neurological diseases. Nature medicine 19, 1524-1528.

Glykys J, Dzhala V, Egawa K, Kahle KT, Delpire E \& Staley K (2017). Chloride Dysregulation, Seizures, and Cerebral Edema: A Relationship with Therapeutic Potential. Trends in Neurosciences 40, 276-294.

Gossen M \& Bujard H (1992). Tight control of gene expression in mammalian cells by tetracyclineresponsive promoters. Proceedings of the National Academy of Sciences of the United States of America 89, 5547-5551.

Hamidi S \& Avoli M (2015). KCC2 function modulates in vitro ictogenesis. Neurobiology of disease 79, 51-58.

Higashima M, Ohno K, Kinoshita H \& Koshino Y (2000). Involvement of GABA(A) and GABA(B) receptors in afterdischarge generation in rat hippocampal slices. Brain research 865,186 193.

Huberfeld G, Wittner L, Clemenceau S, Baulac M, Kaila K, Miles R, et al. (2007). Perturbed Chloride Homeostasis and GABAergic Signaling in Human Temporal Lobe Epilepsy. The Journal of Neuroscience 27, 9866-9873.

Inada $\mathrm{H}$, Watanabe $\mathrm{M}$, Uchida $\mathrm{T}$, Ishibashi $\mathrm{H}$, Wake $\mathrm{H}$, Nemoto $\mathrm{T}$, et al. (2011). GABA regulates the multidirectional tangential migration of GABAergic interneurons in living neonatal mice. PloS one 6, e27048.

Kahle KT, Deeb TZ, Puskarjov M, Silayeva L, Liang B, Kaila K, et al. (2013). Modulation of neuronal activity by phosphorylation of the $\mathrm{K}-\mathrm{Cl}$ cotransporter KCC2. Trends in Neurosciences 36, 726737.

Kahle KT, Khanna AR, Duan J, Staley KJ, Delpire E \& Poduri A (2016). The KCC2 Cotransporter and Human Epilepsy: Getting Excited About Inhibition. The Neuroscientist : a review journal bringing neurobiology, neurology and psychiatry 22, 555-562.

Kahle KT, Merner ND, Friedel P, Silayeva L, Liang B, Khanna A, et al. (2014). Genetically encoded impairment of neuronal KCC2 cotransporter function in human idiopathic generalized epilepsy. EMBO reports $15,766-774$.

Kahle KT, Staley KJ, Nahed BV, Gamba G, Hebert SC, Lifton RP, et al. (2008). Roles of the cationchloride cotransporters in neurological disease. Nature clinical practice Neurology 4, 490503. 
Kaila K, Price TJ, Payne JA, Puskarjov M \& Voipio J (2014). Cation-chloride cotransporters in neuronal development, plasticity and disease. Nature reviews Neuroscience 15, 637-654.

Kralic JE, O'Buckley TK, Khisti RT, Hodge CW, Homanics GE \& Morrow AL (2002). GABA(A) receptor alpha-1 subunit deletion alters receptor subtype assembly, pharmacological and behavioral responses to benzodiazepines and zolpidem. Neuropharmacology 43, 685-694.

Li H, Khirug S, Cai C, Ludwig A, Blaesse P, Kolikova J, et al. (2007). KCC2 interacts with the dendritic cytoskeleton to promote spine development. Neuron 56, 1019-1033.

Liabeuf S, Stuhl-Gourmand L, Gackiere F, Mancuso R, Sanchez Brualla I, Marino P, et al. (2017). Prochlorperazine Increases KCC2 Function and Reduces Spasticity after Spinal Cord Injury. Journal of neurotrauma 34, 3397-3406.

Lillis KP, Kramer MA, Mertz J, Staley KJ \& White JA (2012). Pyramidal cells accumulate chloride at seizure onset. Neurobiology of disease 47, 358-366.

Luttjohann A, Fabene PF \& van Luijtelaar G (2009). A revised Racine's scale for PTZ-induced seizures in rats. Physiology \& behavior $98,579-586$.

Ma J, Matsumoto M, Tanaka KF, Takebayashi H \& Ikenaka K (2006). An animal model for late onset chronic demyelination disease caused by failed terminal differentiation of oligodendrocytes. Neuron glia biology 2, 81-91.

Mayford M, Bach ME, Huang Y-Y, Wang L, Hawkins RD \& Kandel ER (1996). Control of Memory Formation Through Regulated Expression of a CaMKII Transgene. Science 274, 1678-1683.

McKhann GM, 2nd, Wenzel HJ, Robbins CA, Sosunov AA \& Schwartzkroin PA (2003). Mouse strain differences in kainic acid sensitivity, seizure behavior, mortality, and hippocampal pathology. Neuroscience 122, 551-561.

Merner ND, Chandler MR, Bourassa C, Liang B, Khanna AR, Dion P, et al. (2015). Regulatory domain or CpG site variation in SLC12A5, encoding the chloride transporter KCC2, in human autism and schizophrenia. Frontiers in cellular neuroscience 9.

Mody I, Lambert JD \& Heinemann U (1987). Low extracellular magnesium induces epileptiform activity and spreading depression in rat hippocampal slices. Journal of neurophysiology 57, 869-888.

Nabekura J, Ueno T, Okabe A, Furuta A, Iwake T, Shimizu-Okabe C, et al. (2002). Reduction of KCC2 Expression and GABAA Receptor-Mediated

Excitation after In Vivo Axonal Injury. The Journal of Neuroscience 22, 4412-4417. 
Papp E, Rivera C, Kaila K \& Freund TF (2008). Relationship between neuronal vulnerability and potassium-chloride cotransporter 2 immunoreactivity in hippocampus following transient forebrain ischemia. Neuroscience 154, 677-689.

Pathak HR, Weissinger F, Terunuma M, Carlson GC, Hsu FC, Moss SJ, et al. (2007). Disrupted dentate granule cell chloride regulation enhances synaptic excitability during development of temporal lobe epilepsy. The Journal of neuroscience : the official journal of the Society for Neuroscience 27, 14012-14022.

Payne JA, Rivera C, Voipio J \& Kaila K (2003). Cation-chloride co-transporters in neuronal communication, development and trauma. Trends in Neurosciences 26, 199-206.

Payne JA, Stevenson TJ \& Donaldson LF (1996). Molecular characterization of a putative K-Cl cotransporter in rat brain. A neuronal-specific isoform. The Journal of biological chemistry 271, 16245-16252.

Puskarjov M, Seja P, Heron SE, Williams TC, Ahmad F, lona X, et al. (2014). A variant of KCC2 from patients with febrile seizures impairs neuronal $\mathrm{Cl}$ - extrusion and dendritic spine formation. EMBO reports $15,723-729$.

Rivera C, Voipio J, Payne JA, Ruusuvuori E, Lahtinen H, Lamsa K, et al. (1999). The $\mathrm{K}+\mathrm{Cl}$ - cotransporter KCC2 renders GABA hyperpolarizing during neuronal maturation. Nature 397, 251-255.

Rivera C, Voipio J, Thomas-Crusells J, Li H, Emri Z, Sipila S, et al. (2004). Mechanism of activitydependent downregulation of the neuron-specific $\mathrm{K}-\mathrm{Cl}$ cotransporter $\mathrm{KCC} 2$. The Journal of neuroscience : the official journal of the Society for Neuroscience 24, 4683-4691.

Saitsu H, Watanabe M, Akita T, Ohba C, Sugai K, Ong WP, et al. (2016). Impaired neuronal KCC2 function by biallelic SLC12A5 mutations in migrating focal seizures and severe developmental delay. Sci Rep 6.

Silayeva L, Deeb TZ, Hines RM, Kelley MR, Munoz MB, Lee HH, et al. (2015). KCC2 activity is critical in limiting the onset and severity of status epilepticus. Proceedings of the National Academy of Sciences of the United States of America 112, 3523-3528.

Sivakumaran S \& Maguire J (2016). Bumetanide reduces seizure progression and the development of pharmacoresistant status epilepticus. Epilepsia 57, 222-232.

Stodberg T, McTague A, Ruiz AJ, Hirata H, Zhen J, Long P, et al. (2015). Mutations in SLC12A5 in epilepsy of infancy with migrating focal seizures. Nature communications 6. 
Sulis Sato S, Artoni P, Landi S, Cozzolino O, Parra R, Pracucci E, et al. (2017). Simultaneous twophoton imaging of intracellular chloride concentration and $\mathrm{pH}$ in mouse pyramidal neurons in vivo. Proceedings of the National Academy of Sciences 114, E8770-E8779.

Tanaka KF, Ahmari SE, Leonardo ED, Richardson-Jones JW, Budreck EC, Scheiffele P, et al. (2010). Flexible Accelerated STOP Tetracycline Operator-Knockin (FAST): A Versatile and Efficient New Gene Modulating System. Biological Psychiatry 67, 770-773.

Tang X, Kim J, Zhou L, Wengert E, Zhang L, Wu Z, et al. (2016). KCC2 rescues functional deficits in human neurons derived from patients with Rett syndrome. Proceedings of the National Academy of Sciences of the United States of America 113, 751-756.

Titz S, Hormuzdi S, Lewen A, Monyer H \& Misgeld U (2006). Intracellular acidification in neurons induced by ammonium depends on KCC2 function. European Journal of Neuroscience 23, 454-464.

Tornberg J, Voikar V, Savilahti H, Rauvala H \& Airaksinen MS (2005). Behavioural phenotypes of hypomorphic KCC2-deficient mice. The European journal of neuroscience 21, 1327-1337.

Tse K, Puttachary S, Beamer E, Sills GJ \& Thippeswamy T (2014). Advantages of repeated low dose against single high dose of kainate in C57BL/6J mouse model of status epilepticus: behavioral and electroencephalographic studies. PloS one 9, e96622.

Viitanen T, Ruusuvuori E, Kaila K \& Voipio J (2010). The K+-Cl cotransporter KCC2 promotes GABAergic excitation in the mature rat hippocampus. The Journal of physiology 588, $1527-$ 1540.

Wake H, Watanabe M, Moorhouse AJ, Kanematsu T, Horibe S, Matsukawa N, et al. (2007). Early changes in KCC2 phosphorylation in response to neuronal stress result in functional downregulation. The Journal of neuroscience : the official journal of the Society for Neuroscience 27, 1642-1650.

Wang Y, Xu C, Xu Z, Ji C, Liang J, Wang Y, et al. (2017). Depolarized GABAergic Signaling in Subicular Microcircuits Mediates Generalized Seizure in Temporal Lobe Epilepsy. Neuron 95, 92105.e105.

Watanabe M, Wake H, Moorhouse AJ \& Nabekura J (2009). Clustering of neuronal K+-Clcotransporters in lipid rafts by tyrosine phosphorylation. The Journal of biological chemistry 284, 27980-27988.

Woo NS, Lu J, England R, McClellan R, Dufour S, Mount DB, et al. (2002). Hyperexcitability and epilepsy associated with disruption of the mouse neuronal-specific $\mathrm{K}-\mathrm{Cl}$ cotransporter gene. Hippocampus 12, 258-268. 
Wu H, Che X, Tang J, Ma F, Pan K, Zhao M, et al. (2016). The K(+)-Cl(-) Cotransporter KCC2 and Chloride Homeostasis: Potential Therapeutic Target in Acute Central Nervous System Injury. Molecular neurobiology 53, 2141-2151.

\section{Figure Legends}

Figure 1. A conditional transgenic mouse that overexpresses KCC2. A. The tTA-CAMKII $\alpha$ mouse was crossed with a novel transgenic mouse in which the tetO tetracycline responsive expression cassette was inserted immediately upstream of the $\mathrm{KCC} 2$ translation initiation site. Conditional overexpression of $\mathrm{KCC} 2$ in neurons expressing tTA was achieved upon withdrawal of Doxycycline (Dox) from the diet. B. In situ hybridization of KCC2 in sagital slices of a control, wild type (WT) C57B16 mouse and a transgenic mouse positive for expression of tTA-CaMKII $\alpha$ and $\mathrm{KCC} 2-\mathrm{tetO}(+/+)$ that had Dox withdrawn from the diet for 48 hrs. C. Western blot for KCC2 in cortex, hippocampus and amygdala in wild type control mice (lane 1), and in tTA-KCC2 (+/+) mice continuously fed with Dox (lane 2), in which Dox was withdrawn for 7 days (lane 3) and in which Dox was withdrawn for 7 days and then reintroduced for 21 days (lane 4). Left panel shows representative blots for KCC2 and $\beta$ actin, while the right panel shows the mean data for the ratio of $\mathrm{KCC} 2$ to $\beta$-actin expression, normalised to that seen in the WT tissues, $n=3$ different mice for each lane.

Figure 2. KCC2 membrane transport function measured using BCECF fluorescence. A. Example of loading and baseline fluorescence in a hippocampal slice from tTA-KCC2 mice maintained on Dox (Dox On, left) or with Dox withdrawn from the diet for 7 days (Dox Off, right). B. Changes in BCECF fluorescence intensity in single neurons in response to bath application of $\mathrm{NH}_{4} \mathrm{Cl}(10 \mathrm{mM})$ in control conditions, and then 10 minutes later in the presence of furosemide. The fluorescence has been normalised to the average of that observed in the $1^{\text {st }} 30$ secs of the recording. The data come from neurons shown in A. C. 
Averaged changes in normalised fluorescence in response to $\mathrm{NH}_{4} \mathrm{Cl}$. The graphs plot the peak increase in FI and the KCC2-mediated acidification decay, measured 2 minutes after returning to control bath solution. The bar graph shows mean $\pm \mathrm{SEM}$, while the points and connecting lines show data from each individual experiment, $*=$ significantly different between Dox on mice $(n=5)$ and Dox Off mice $(n=4$; unpaired t-test, $p=0.03)$.

Figure 3. Effects of KCC2 overexpression on locomotion and exploratory behaviours. A. Total distanced travelled during 10 mins in an open field (left) and during 5 minutes in the elevated plus maze test (right). B. Proportion of the time spent in the centre area during 10 mins in the open field (right panel), and proportion of time spent in the open arms during 5 mins in the elevated plus maze test (right). Control refers to combined data for both Wild type (tTA-KCC2 negative) and KCC2 (tTA negative) mice, and sample size is shown in parenthesis after each group. Column graphs show mean and SEM, while individual symbols represent individual data points. There were no significant differences between mouse groups in any of these parameters (Kruskal-Wallis, and Dunn's pot-hoc comparison tests).

Figure 4. Basal properties of field potentials and $G A B A_{A}$-receptor mediated inhibition in hippocampal slices from transgenic mice. A. Schematic illustration of experimental setup. The population spike was recorded from the CA1 pyramidal cell layer in response to stimulation of Schaeffer collateral afferents arising from CA3 neurons. B. Increasing stimulus intensity resulted in an increasing population spike amplitude up until a maximum. There was no difference in this input-output relationship between any of the mouse groups at either room temperature (left panel) or at elevated temperature (right panel). Population spike amplitudes were normalised to those obtained at a stimulus intensity of $30 \mathrm{~V}$. Stimulus duration was constant at $0.2 \mathrm{~ms}$. C. Representative field potentials recorded from hippocampal slices from tTA-KCC2 mice raised with Dox (DOX ON, upper traces) or with Dox withdrawn from the diet for 6-10 days (DOX OFF, lower traces), under control 
conditions and in the presence of different concentrations of the $\mathrm{GABA}_{\mathrm{A}}$ receptor agonist muscimol. D. Muscimol concentration response curves for population spike amplitude in hippocampal slices from KCC2 and tTA-KCC2 mice, raised with Dox in the diet (Dox ON) or that had Dox withdrawn from the diet for 6-10 days (Dox OFF). Data is derived from 6 slices (from 4-5 mice) in each group. Curves represent the Hill equation fit to the mean data $\left(r^{2}>0.9\right)$

Figure 5. Overexpression of KCC2 confers resistance to seizure activity in vitro. A. Representative field potential responses recorded in CA1 cell layer in response to Schaeffer collateral stimulation. Left panels show a single stimulus evoked response. Right hand panels show the response to a $100 \mathrm{~Hz}, 1 \mathrm{sec}$ tetanus. In slices from tTA-KCC2 mice raised with Dox (Dox ON) the tetanus induced spontaneous afterdischarges (ADs), which were absent in slices from Dox-off tTA-KCC2 mice. B. Plot of the mean number of ADs induced by tetanic stimulation, in slices derived from the mice groups as indicated $(n=6-7$ slices from 5 mice in each group). The number of ADs in each slice was quantified by taking the average from the $4^{\text {th }}$ to $6^{\text {th }}$ tetanus (applied every 10 mins), by which time the response to the tetanus had stabilized. Overexpression of KCC2 resulted in a significant decrease in the mean number of ADs $(* *=p<0.01$; ANOVA and post-hoc Bonferroni’s test.) C. Representative field potentials recorded from CA1 pyramidal cell layer in control conditions (Baseline), and when $\mathrm{Mg}^{2+}$ was removed from the perfusate $\left(\right.$ Zero $\mathrm{Mg}^{2+} / \mathrm{High}^{+}$. Note the appearance of spontaneous discharges (spikes) upon perfusion with $\mathrm{Mg}^{2+}$-free solution. D. Quantification of the latency for appearance of spontaneous spikes in zero- $\mathrm{Mg}^{2+}$ perfusate (left) and the frequency of these spontaneous spikes (right). Data is derived from 6 slices (from 4-5 mice) in each experimental group as indicated. Overexpression of KCC2 resulted in a significant increase in spontaneous spike latency, and a significant decrease in the frequency of spontaneous discharges $(* *=\mathrm{p}<0.01)$; ANOVA and post-hoc Bonferroni’s test. 
Figure 6. KCC2 upregulation mitigates against the progression into Kainic Acid induced Status Epilepticus. A, B. Representative plots of the timecourse of seizure phenotypes for each of five tTA-KCC2 (+/+) mouse raised on Dox (Dox on, A), and for each of five tTAKCC2 $(+/+)$ mice in which Dox was withdrawn from the diet for at least 6 days (Dox off, B). The time of KA injections $(5 \mathrm{mg} / \mathrm{kg}$, ip) are indicated by arrow heads (bold arrowhead indicates $10 \mathrm{mg} / \mathrm{kg}$, ip). Large bold symbol indicates seizure-induced mortality. C. Mean group data plotting the total dose of kainic acid required to elicit SE. The average dose required to elicit $\mathrm{SE}$ is indicated by the bar graphs (mean $\pm \mathrm{SEM})$, while data for from each individual mouse also shown. If no SE was observed after $50 \mathrm{mg}$ total $\mathrm{KA}$, this was assigned a data point of $50 \mathrm{mg}$. A significantly lower dose was required for SE in the Do-on tTAKCC2 control mice as compared to the KCC2 overexpressing tTA-KCC2 Do off mice (*** $\mathrm{p}<0.0001$, ANOVA and post-hoc Bonferroni’s). 


\section{Figure 1}

A.

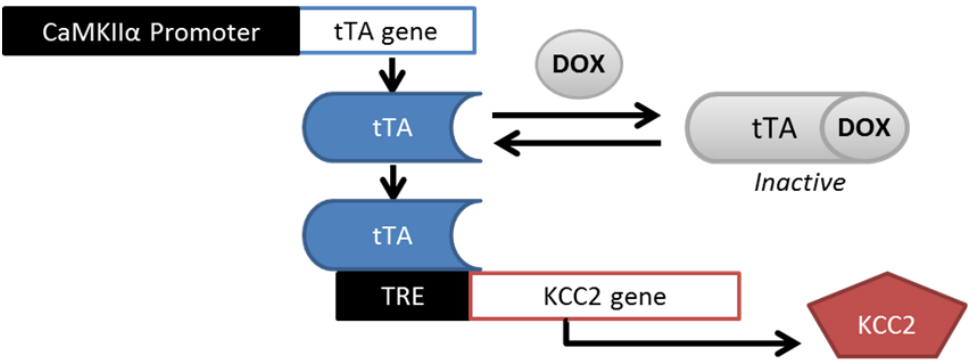

B.

(i) Wild-type mouse

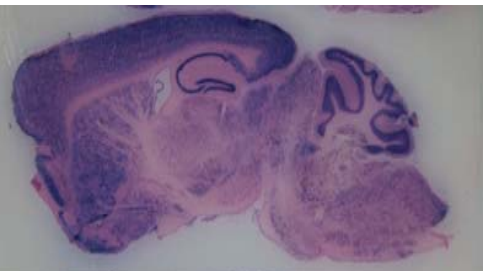

(ii) tTA-KCC2, Dox Off

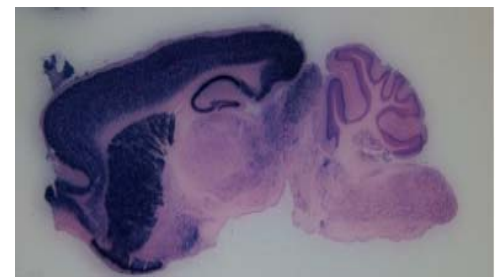

C.

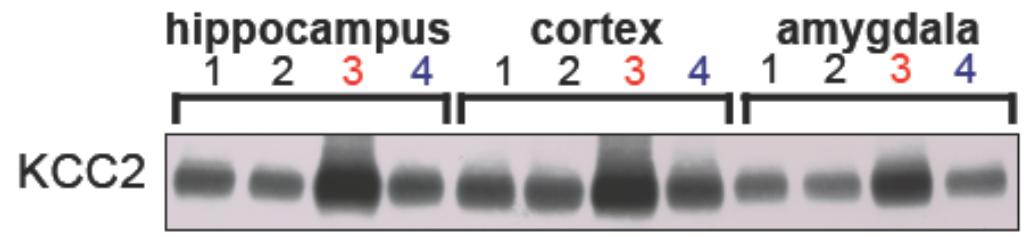

ß-actin

Lane 1 = wild type

Lane 2 = tTA-KCC2 Dox On
Lane 3 = tTA-KCC2 Dox Off

Lane 4 = tTA-KCC2 Dox Return

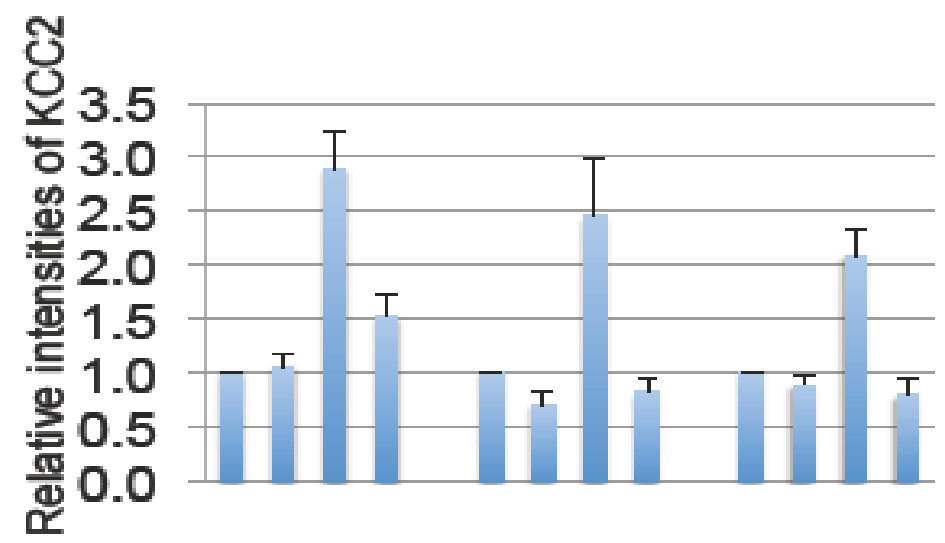




\section{Figure 2}

A. Dox On

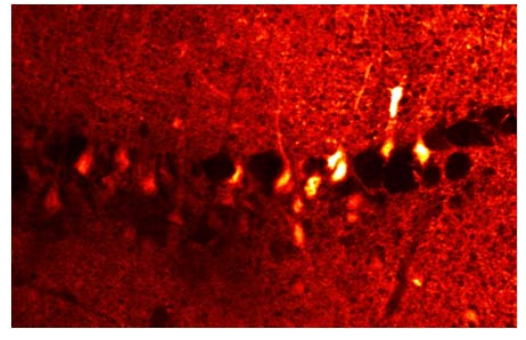

Dox Off

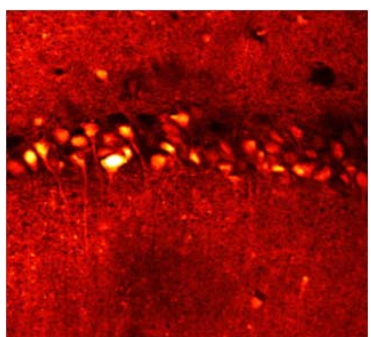

B.

DOX ON

DOX OFF

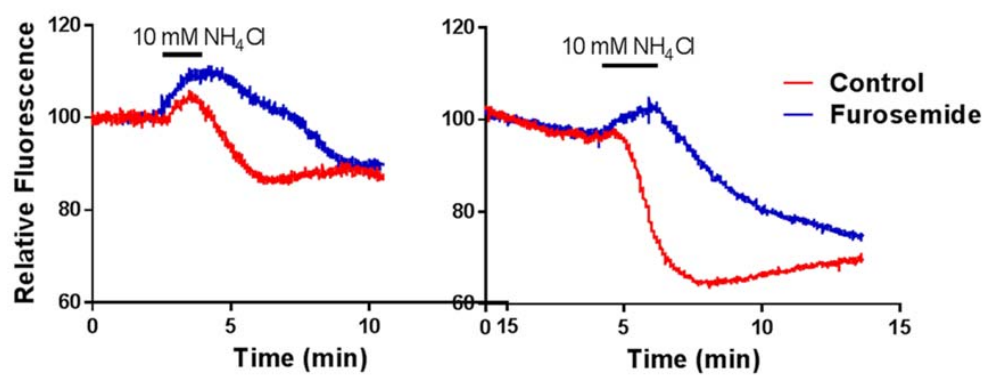

C.

DOX ON

DOX OFF
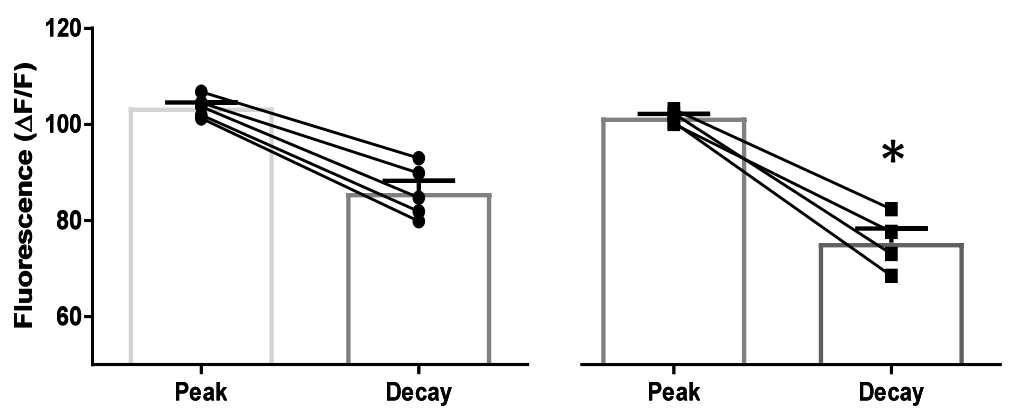


\section{Figure 3}

A.

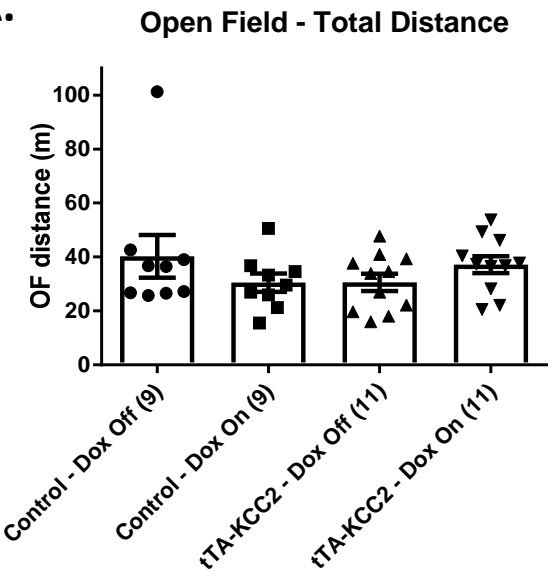

B.

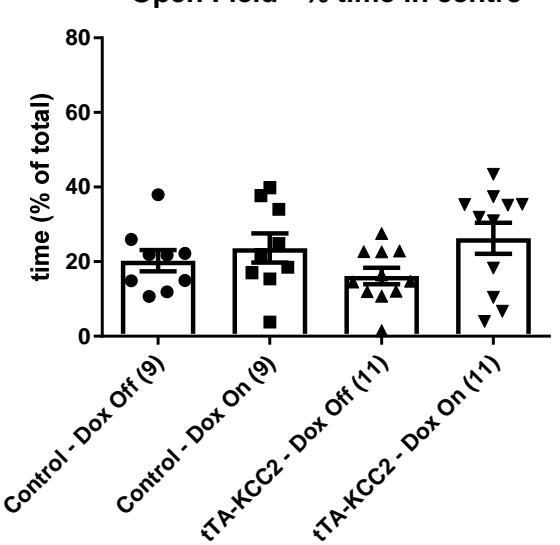

Elevated Plus Maze - Total Distance

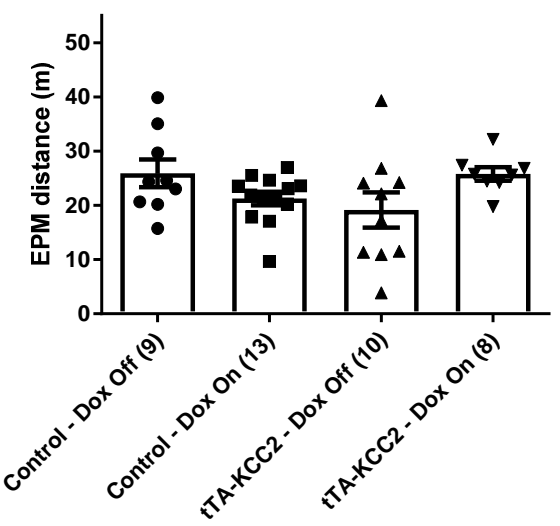

Elevated PLus Maze - Open Arm Time

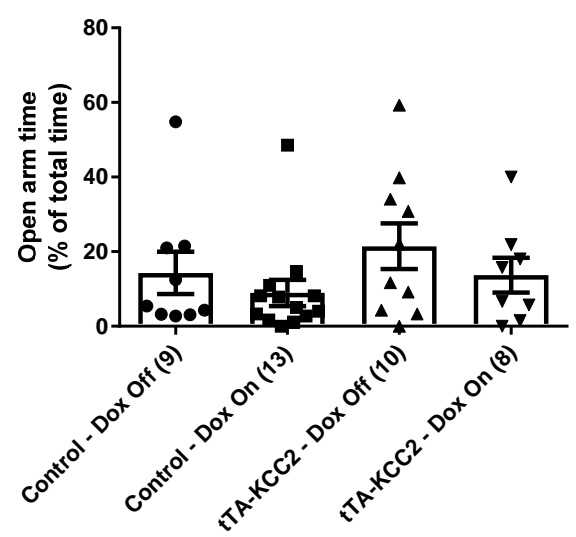


bioRxiv preprint doi: https://doi.org/10.1101/253831; this version posted January 30,2018 . The copyright holder for this preprint (which was not certified by peer review) is the author/funder, who has granted bioRxiv a license to display the preprint in perpetuity. It is made available under aCC-BY-NC-ND 4.0 International license.

\section{Figure 4}

A.

B.

$22-24^{\circ} \mathrm{C}$

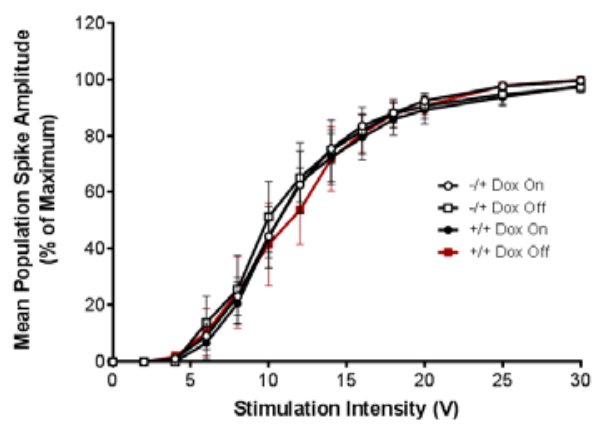

$32-34{ }^{\circ} \mathrm{C}$

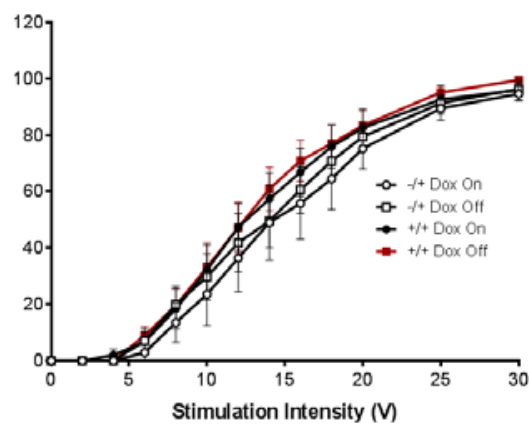

C.

Baseline
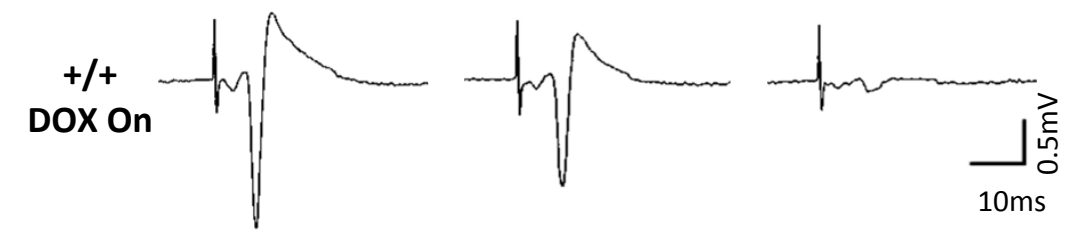

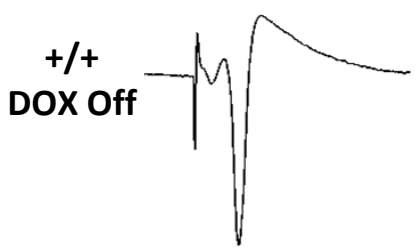

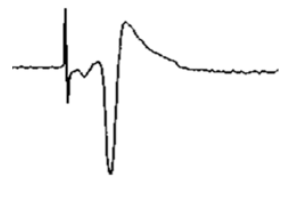

$1 \mu \mathrm{M}$

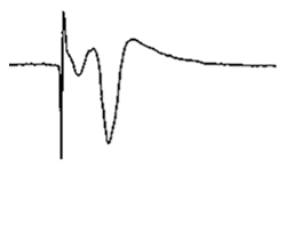

$10 \mu \mathrm{M}$

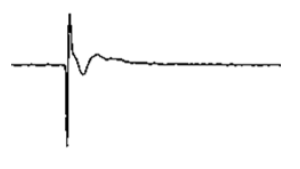

D.

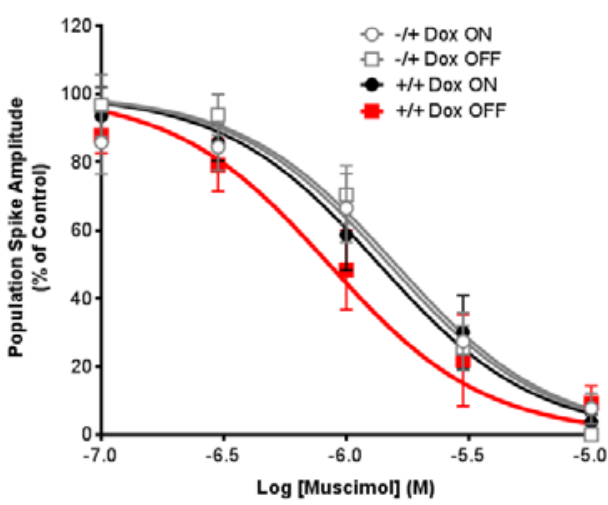




\section{Figure 5}

A.
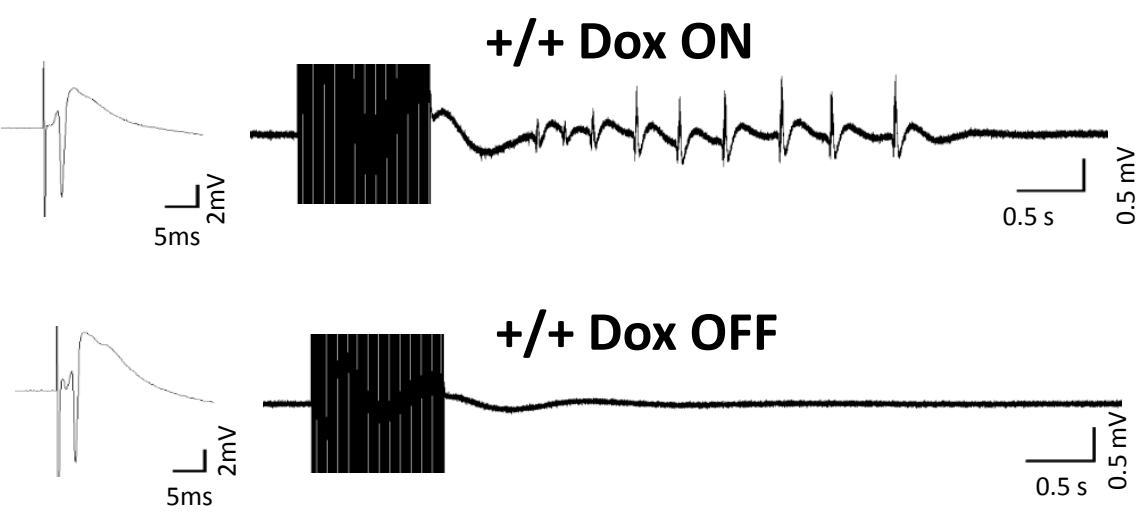

B.

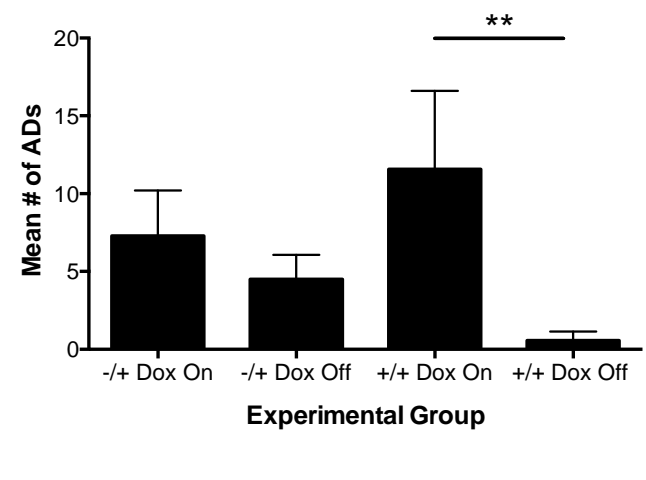

C. Baseline

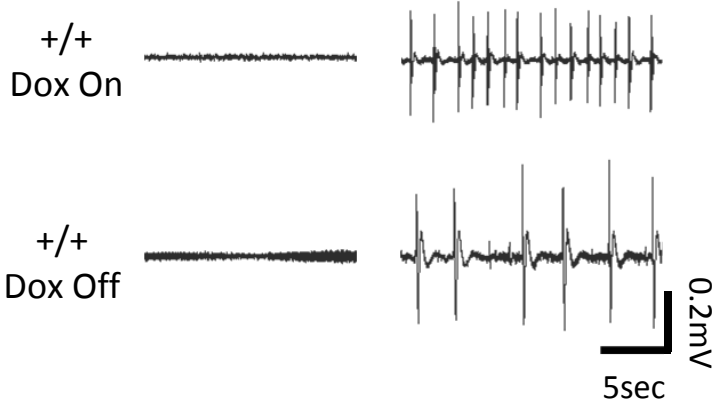

D.

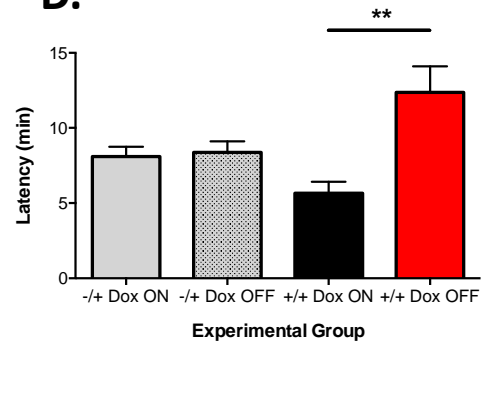

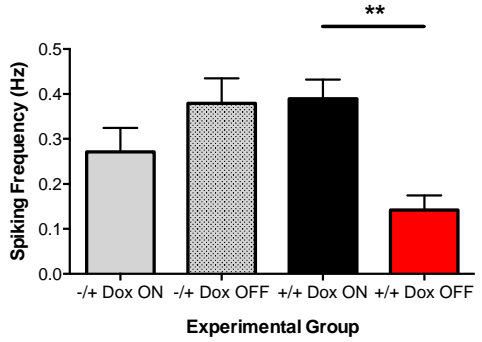


bioRxiv preprint doi: https://doi.org/10.1101/253831; this version posted January 30,2018 . The copyright holder for this preprint (which was not certified by peer review) is the author/funder, who has granted bioRxiv a license to display the preprint in perpetuity. It is made available under aCC-BY-NC-ND 4.0 International license.

\section{Figure 6}

A.

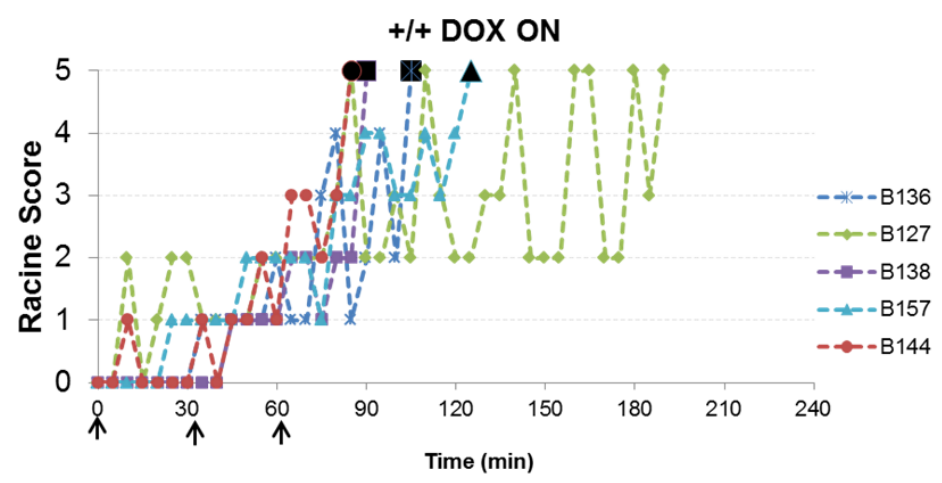

B.

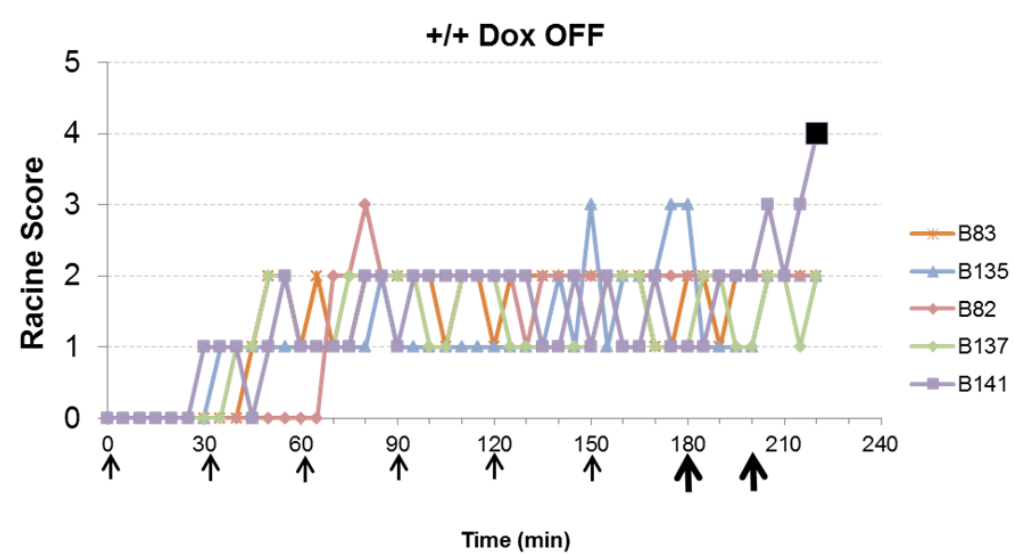

Dose for KA-induced Status

c.

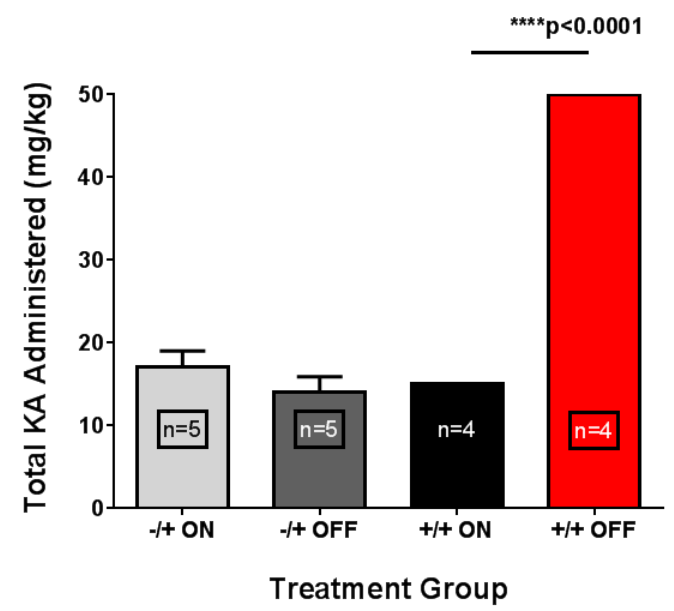




\section{Supplemental Figure 1}

Days off doxycycline diet

KCC2

$140 \mathrm{kDa}$
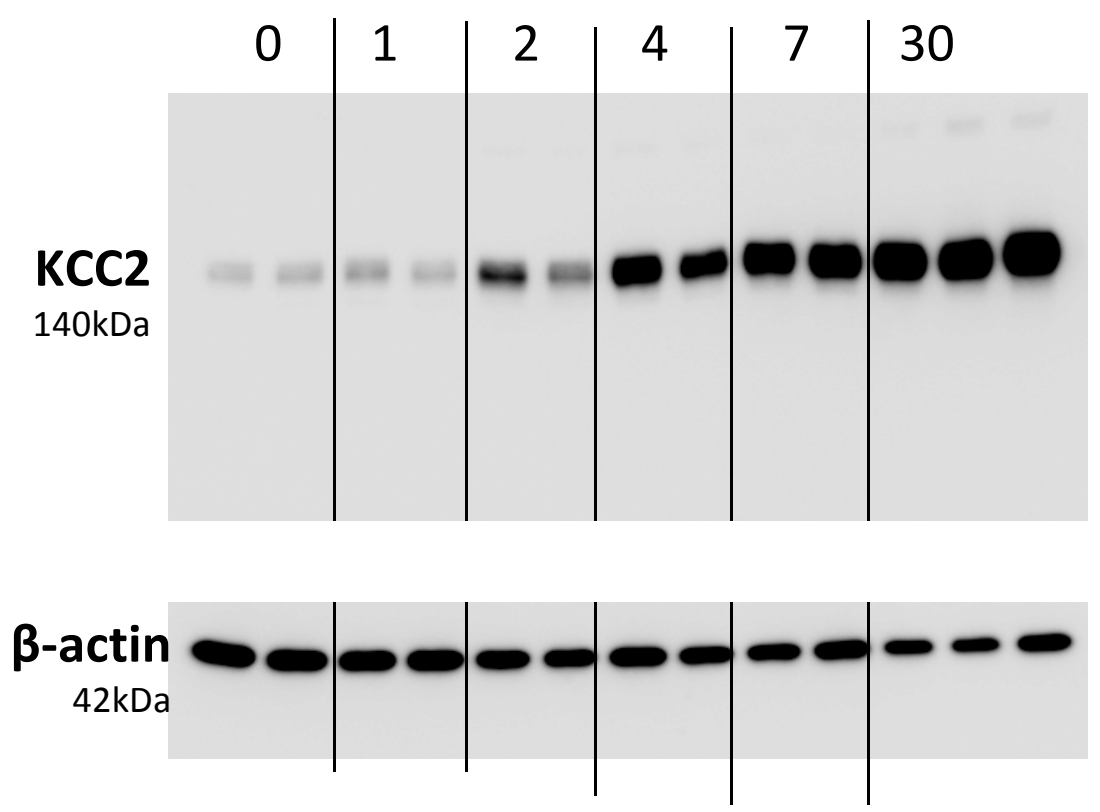

Supplemental Figure 1. Time-course of Dox withdrawal induced KCC2 overexpression. Upper panel shows sample western blots for KCC2 in hippocampal tissues from 2 different tTA-KCC2 mice after withdrawing Dox from their diets for 0-30 days as indicated $(0$ days $=$ Dox on). Lower panel shows immunoblot for beta-actin from same tissue samples. 


\section{Supplemental Figure 2}

A.

VEH + PTZ - Latency to Level 3 "1st Twitch"

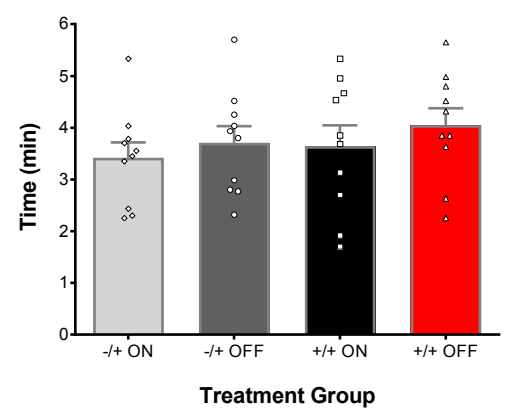

B. DZP + PTZ - Latency to Level 3 "1st Twitch"

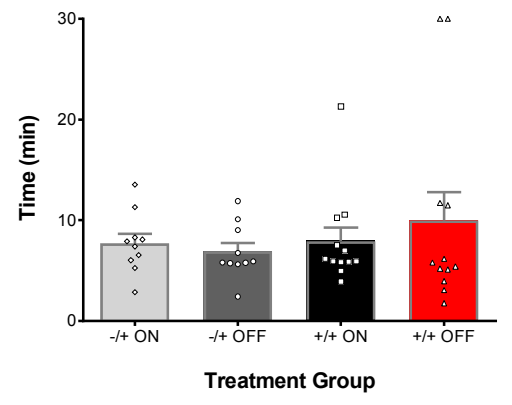

$\mathrm{VEH}+\mathrm{PTZ}$

Seizure Score (30 $\mathrm{min})$

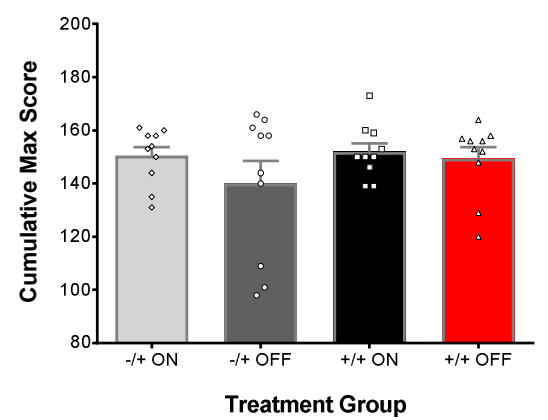

PTZ + DZP Score (30 min)

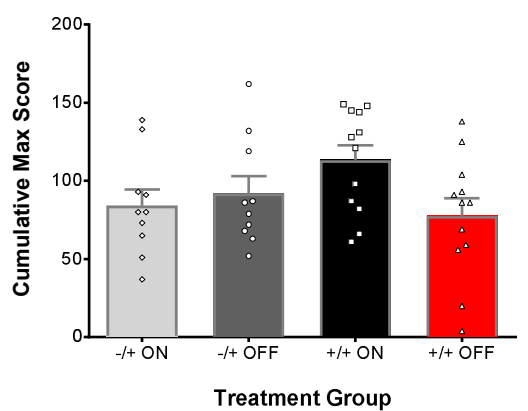

Supplemental Figure 2. Pentyltetrazole induced seizure phenotypes are unaffected by KCC2 overexpression A. Mean group data showing the latency to the $1^{\text {st }}$ appearance of a generalized clonic seizure ("twitch") in response to PTZ (85 mg, kg, sc) after saline (left) or diazepam (right) pretreatment. B. Mean group data showing the cumulative seizure score during the 30 (left) or 60 (right) mins following administration of PTZ ( $85 \mathrm{mg} / \mathrm{kg}, s c)$ with saline (left) or diazepam (right) pretreatment. In $A$ and $B$, results from KCC2 and tTA-KCC2 mice, with and without Dox in the diet are shown ( $n=10-13$ in each group). Column graphs represent mean \pm SEM, and data from each individual mouse also shown. There was no significant effect of KCC2 overexpression on any of these parameters (ANOVA and post-hoc Bonferroni comparison). 